\title{
EL "PRAGMATISMO PRINCIPISTA" DE LA POLÍTICA EXTERIOR DE MÉXICO EN LOS VOTOS SOBRE CUBA EN LA OEA (1962-1964)
}

\author{
THE "PRINCIPLED PRAGMATISM" OF MEXICAN \\ FOREIGN POLICY IN THE VOTES ON CUBA \\ AT THE OAS (1962-1964)
}

\section{LE «PRAGMATISME DES PRINCIPES» DE LA POLITIQUE ÉTRANGÈRE DU MEXIQUE DANS LES VOTES CONCERNANT CUBA À L'OEA (1962-1964)}

\author{
Rafael Velázquez Flores* \\ Universidad Autónoma de Baja California \\ rafael.velazquez@uabc.edu.mx
}

RESUmen: El objetivo central de este artículo es explicar las razones por las cuales el gobierno de Adolfo López Mateos (ALM) emitió tres votos diferentes en tres reuniones distintas de la Organización de los Estados Americanos (OEA), en un tiempo relativamente corto, sobre temas vinculados a Cuba y la política anticomunista de Estados Unidos. Para ello, el trabajo analiza, a partir de la noción de los win-sets (conjuntos ganadores) de la teoría del juego del doble nivel de Robert Putnam, el proceso de toma de decisiones de la política exterior de México frente a Cuba en el marco de esas tres reuniones. Los votos diferenciados se explican en función del tamaño de los win-sets en cada caso, los cuales estaban determinados por distintas coyunturas internas y externas que se presentaron en cada momento. La decisión

* El autor desea agradecer los valiosos comentarios de los dos dictaminadores anónimos. Sus observaciones ayudaron a mejorar sustantivamente la versión final de este trabajo. Asimismo, el autor agradece a las siguientes personas por su apoyo ofrecido al Dr. Jorge A. Schiavon, por sus puntuales recomendaciones sobre el primer borrador; a Renata Keller, por facilitar sus obras; a Sabrina Elizabeth Briseño Delgado, estudiante de la UABC, por el apoyo para la localización de fuentes; a Luis Ernesto Casillas Márquez, por la información proporcionada desde Washington; y a Jorge Alberto Escamilla Chimal, del Instituto Matías Romero (IMR), por su gestión para poder consultar los archivos históricos de la SRE. 
dependía, principalmente, del interés del gobierno y del peso de los grupos de presión, tanto internos como externos, que en ese momento tenían interés en el tema, y de la situación nacional e internacional que en ese entonces prevalecía.

El ensayo busca demostrar la siguiente hipótesis: en la opinión pública mexicana, existe una interpretación generalizada de que el gobierno de ALM apoyó a Cuba en esas reuniones de la oEA. Sin embargo, aquí se busca probar que, en los hechos, México se alineó a los intereses de Estados Unidos y no a los del régimen de Castro.

Palabras clave: pragmatismo principista; proceso de toma de decisiones; política exterior; México; Cuba; Estados Unidos; juego del doble nivel; teoría de los win-sets; Organización de los Estados Americanos, oEA.

Abstract: The central aim of this paper is to explain the reasons why the government of Adolfo López Mateos (ALM) produced three different votes at three different meetings of the Organization of American States (OAS), over a relatively brief period, on issues relating to Cuba and the anti-communist policy of the United States. To do this it analyzes the concept of the win-sets of Robert Putnam's two-level game theory, the decision-making process of Mexico's foreign policy towards Cuba in the context of these three meetings. The different votes are explained on the basis of the size of the win-sets in each case, which were determined on the basis of different internal and external circumstances that are presented in each moment. The decision depended principally on the interest of the government and the impact of the pressure groups, both internal and external, that had an interest in the issue at the time and in the prevailing domestic and international situation.

The essay seeks to demonstrate the following hypothesis: in Mexican public opinion, there is a widespread view that the government of ALm supported Cuba at these meetings of the oAs. However, the aim here is to show that in fact, Mexico was aligned with the interests of the United States and not with those of the Castro regime.

Keywords: principled pragmatism; decision-making process; foreign policy; Mexico; Cuba; United States; two-level game; theory of win-sets; Organization of American States, ozA.

\section{Traducción de Fionn Petch, CM Idiomas}


RÉsumÉ: L'objectif principal de cet article est d'expliquer les raisons pour lesquelles le gouvernement d'Adolfo López Mateos (ALM) a émis trois votes différents lors de trois réunions différentes de l'Organisation des États Américains (OEA), dans un laps de temps relativement court, sur des questions concernant Cuba et la politique anticommuniste des États-Unis. Pour ce faire, l'ouvrage analyse, à partir de la notion des win-sets (ensembles gagnants) de la théorie des jeux à deux niveaux de Robert Putnam, le processus décisionnel de la politique étrangère mexicaine vis-à-vis de Cuba dans le cadre de ces trois réunions. Les votes différenciés sont expliqués en fonction de l'importance des win-sets dans chaque cas, lesquels ont été déterminés à partir de différentes situations internes et externes qui se sont produites à chaque instant. La décision dépendait principalement de l'intérêt du gouvernement et du poids des groupes de pression, aussi bien internes qu'externes, qui à l'époque s'intéressaient à cette question, ainsi qu'à la situation nationale et internationale qui régnait alors.

L'essai cherche à démontrer l'hypothèse suivante: dans l'opinion publique mexicaine, il y a une interprétation générale selon laquelle le gouvernement Alm a soutenu Cuba lors de ces réunions de l'oea. Cependant, le but ici est de prouver qu'en fait, le Mexique s'est aligné sur les intérêts des ÉtatsUnis et non sur ceux du régime de Castro.

Mots clés: pragmatisme de principes; processus de prise de décision; police étrangère; Mexique; Cuba; États Unis; jeu à deux niveaux; théorie des win-sets; Organisation des États Américains, oEA.

\section{Traducción de Rafael Segovia, CM Idiomas}

Fecha de recepción: agosto de 2020

Fecha de aceptación: abril de 2021 
INTRODUCGIÓN

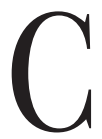

on el triunfo de la Revolución cubana en 1959, el sistema internacional experimentó cambios sumamente significativos. En primer lugar, la instalación de un gobierno comunista en la isla trajo la Guerra Fría a la región de las Américas. En años anteriores, el asunto parecía concentrarse en Europa y en algunas partes de Asia. Sin embargo, para esos momentos, Estados Unidos tenía a 100 millas de su territorio una amenaza real derivada de la confrontación con la Unión Soviética. En México, hubo impactos internos debido a la aparición de movimientos sociales y de organizaciones de corte izquierdista que apoyaban al régimen de Fidel Castro. Además, en contrapartida, había grupos conservadores que demandaban que el gobierno mexicano asumiera una posición anticomunista. Por otro lado, mientras Washington pedía a la Ciudad de México su apoyo en su enfrentamiento con la isla, el gobierno de Cuba solicitaba a México la defensa de los principios de no intervención y autodeterminación. En otras palabras, la administración del entonces presidente Adolfo López Mateos (ALM) se enfrentaba a un dilema de difícil solución. Para entonces, la relación con Cuba se convirtió en uno de los temas más destacados de la política exterior de México por sus implicaciones internas. En medio de esta vinculación estaba Estados Unidos. Es decir, no es posible entender la relación bilateral Ciudad de México-La Habana sin considerar el factor Washington. Por lo tanto, era una relación de naturaleza tripartita.

Entre 1962 y 1964, hubo tres reuniones en el marco de la Organización de los Estados Americanos (oEA) de alto impacto para la política regional, en las que se trató el tema de Cuba. Los votos de México en esas sesiones fueron importantes por sus efectos en el ámbito interno y externo. La primera reunión tuvo lugar en Punta del Este, Uruguay, en enero de 1962. Era la vin Reunión de Consulta de Ministros de Relaciones Exteriores (RCMRE) de la OEA, que había sido 
convocada por Colombia para tratar asuntos relacionados con el nuevo régimen comunista de Fidel Castro. De entre varias resoluciones, la más importante proponía la exclusión de Cuba de la organización regional. En esa ocasión, el voto de México fue abstención debido a que los estatutos de la oEA no contemplaban, desde la perspectiva del gobierno mexicano, la posibilidad de expulsar a un miembro. La segunda reunión fue convocada por Washington en medio de la crisis de los misiles en octubre de 1962, cuando la Unión Soviética había instalado cohetes nucleares en la isla. El gobierno de John F. Kennedy (JFK) convocó a una reunión de emergencia del Consejo de la oEA para exigir el retiro de los misiles. En esta ocasión, México votó a favor de la resolución. Finalmente, la tercera reunión fue la IX RCMRE, la cual fue convocada por Venezuela. La propuesta principal era que los miembros de la oEA rompieran relaciones diplomáticas con Castro. En su momento, México votó en contra de la resolución. En resumen, la administración del entonces presidente López Mateos emitió tres sufragios distintos en un lapso relativamente corto sobre un mismo país. Los temas tenían cierta similitud, pero había diferencias importantes. Los tres estaban enmarcados en la confrontación de Estados Unidos con el comunismo.

Sobre este tema, un problema de la literatura es que hay una amplia confusión en algunas fuentes sobre los votos que México emitió en esas tres reuniones. Varios autores plantean que el voto en la primera fue en contra, cuando en realidad fue abstención. Tal vez la confusión se deba a que, en la tercera reunión, efectivamente el voto fue en contra, pero no hay claridad de que hubiera otras reuniones. Por lo tanto, una de las motivaciones de este artículo es clarificar el asunto.

En este orden de ideas, el objetivo principal del presente ensayo es explicar las razones del gobierno de ALM para emitir tres votos diferentes en tan corto tiempo sobre un tema relativamente similar. Para ello, el trabajo recurrirá a la noción de los win-sets de la teoría del juego del doble nivel, de 
Robert Putnam, para analizar el proceso de toma de decisiones de la política exterior de México frente a Cuba en el marco de esas tres reuniones. Los votos diferenciados se explican debido a las distintas coyunturas internas y externas que se presentaron en cada momento. La decisión dependía, principalmente, del tamaño de los win-sets en cada caso; es decir, de las preferencias y las coaliciones de los grupos internos, las instituciones formales e informales nacionales, y de las estrategias de los negociadores externos. La hipótesis que se propone demostrar este artículo es la siguiente: en la opinión pública mexicana, existe una interpretación generalizada de que el gobierno de ALM apoyó a Cuba en esas reuniones de la oEA. Sin embargo, este texto busca probar que, en los hechos, México se alineó a los intereses de Estados Unidos y no a los del régimen de Castro. Para ello, el artículo se divide en cinco partes. La primera presenta el encuadre teórico que servirá de guía para el desarrollo del trabajo. La segunda parte hace una revisión de la literatura existente sobre el tema. La tercera analiza el caso del voto de México en la viII Reunión de Consulta de Ministros de Relaciones Exteriores (VIII-RCMRE) de la OEA de enero de 1962, en la que se buscaba excluir a Cuba de esa organización. La cuarta sección revisa el voto mexicano en la reunión de emergencia del Consejo de la ozA de octubre de 1962, convocada en el marco de la crisis de los misiles. La última parte examina el voto en contra de México en la Ix Reunión de Consulta de Ministros (IX-RCMRE) de julio de 1964, en la que se planteaba el rompimiento de relaciones diplomáticas con Cuba.

El ENCUADRE TEÓRICO-CONCEPTUAL: EL PROCESO DE TOMA DE DECISIONES, EL JUEGO DEL DOBLE NIVEL Y EL PRAGMATISMO PRINCIPISTA

En esta primera parte se busca establecer las bases teórico-metodológicas y conceptuales del artículo. Hay tres elementos a destacar. En primer lugar, es importante describir 
brevemente las características fundamentales del proceso de toma de decisiones de la política exterior mexicana, tanto en su esfera formal como en la informal, para advertir más adelante cómo funcionó en los casos de estudio. En segundo lugar, es necesario establecer los principales supuestos teóricos del juego del doble nivel, de Robert Putnam, con especial énfasis en la noción de los win-sets. Estos elementos guiarán, desde una perspectiva metodológica, la orientación del artículo. Finalmente, es importante desarrollar el concepto de "pragmatismo principista", dado que el término es central para los efectos de este trabajo.

Estudiar el proceso de toma de decisiones de la política exterior de México es complicado por varias razones. La primera es que no hay mucha literatura en el país que se enfoque exclusivamente a analizar esta actividad. La segunda es que la información sobre cómo se llevó a cabo el proceso decisorio es escasa. La tercera es que esta actividad cuenta con un proceso formal y otro informal. Por un lado, la Constitución y otros reglamentos establecen el marco jurídico que norma esta labor. Por el otro, existen prácticas y costumbres del sistema político que también influyen en la política exterior.

En el ámbito formal, la carta magna establece que la política exterior es prácticamente una corresponsabilidad de los poderes Ejecutivo y Legislativo. El artículo 89, fracción X, marca que el presidente está a cargo de "dirigir" las relaciones internacionales del país. De acuerdo con esta normatividad, el presidente debe basar esta actividad en los principios tradicionales de la política exterior mexicana, que son la no intervención, la autodeterminación, la igualdad jurídica, la solución pacífica de las controversias, entre otros. Esto implica que, en sus decisiones, el jefe del Ejecutivo tiene guiarse a partir de esos principios. ${ }^{1}$ En otras palabras, por mandato

${ }^{1}$ Si bien los principios no estaban todavía incluidos en la Constitución en el periodo de estudio, los gobiernos mexicanos de la época basaban su política exterior en la Doctrina Carranza, la cual establece los 
constitucional, la política exterior debe ser principista. Existen también otros reglamentos y leyes que le dan formalidad al proceso de toma de decisiones. Por ejemplo, la Ley Orgánica de la Administración Pública Federal (LOAPF) establece que la Secretaría de Relaciones Exteriores (SRE) está a cargo de representar al país y coordinar la labor internacional de otras dependencias de gobierno. En efecto, hoy día muchas secretarías de Estado tienen una agenda amplia de vínculos con sus pares en el exterior o atienden temas de su competencia en el ámbito mundial. Por ejemplo, la Secretaría de Economía está a cargo de la firma de acuerdos de libre comercio; la de Hacienda tiene funciones sobre deuda externa y aduanas; las de Gobernación, Defensa Nacional y la de Marina están a cargo de la seguridad del país. Asimismo, otras dependencias tienen vínculos con el exterior, como son Turismo, Educación, Medio Ambiente, Salud, etcétera. Según la LOAPF, la SRE está a cargo de coordinar toda la actividad internacional de todas las dependencias mencionadas. ${ }^{2}$

En el ámbito legislativo, el artículo 76 establece que el Senado de la República tiene la facultad de "analizar" la política exterior que le presente el Ejecutivo. Asimismo, los senadores tienen las siguientes funciones: "aprobar" los tratados que hayan sido firmados por el Ejecutivo; "ratificar" los nombramientos diplomáticos; "autorizar" la salida de tropas militares fuera del país; autorizar la salida del presidente si el viaje dura más de siete días, entre otras funciones. Por su parte, la Cámara de Diputados no tiene funciones específicas en materia de política exterior. La Constitución busca establecer una

principios de no intervención, igualdad jurídica y solución pacífica, entre otros. Fue hasta 1987 cuando el Congreso aprobó una reforma para incluirlos en el artículo 89, fracción X.

2 También existen otras leyes que le dan forma al marco jurídico de la política exterior de México, como la Ley del Servicio Exterior Mexicano, la Ley para la Celebración de Tratados, la Ley de Cooperación Internacional para el Desarrollo, entre otras. Tanto la Constitución como las leyes mencionadas representan el núcleo formal del proceso de toma de decisiones de la política exterior en manos del Ejecutivo. 
separación de poderes para que exista una mutua supervisión y un proceso de contrapesos en la toma de las decisiones. Así, el poder no recaería en una sola figura. Sin embargo, en la práctica, el presidente de México ha tenido mayor peso en el proceso de toma de decisiones de la política exterior. Esta realidad se maximiza cuando el tema es de alto perfil, como fue el caso de la política exterior frente a Cuba. En este caso, el Congreso se supeditó a las preferencias del presidente.

Normalmente, existen dos tipos de decisiones de política exterior. Las de bajo perfil y las de alta prioridad. Es usual que la burocracia diplomática se haga cargo de los asuntos cotidianos. Es decir, el Ejecutivo deja en manos de los expertos el proceso y la decisión cuando son temas de bajo perfil. En este tipo de acciones suele prevalecer el principismo. Es decir, los funcionarios basan su criterio en los principios tradicionales. Sin embargo, cuando son temas de alto interés nacional, es común que el proceso recaiga en la figura presidencial y en sus más cercanos colaboradores. En estos casos, el jefe del Ejecutivo suele recurrir al pragmatismo con el objetivo de avanzar los intereses nacionales del país. En estos casos, es complicado identificar el proceso de toma de decisiones porque normalmente el presidente las decide en un círculo cerrado y, a veces, no se puede obtener información de quiénes participaron, qué opciones se discutieron y qué factores influyeron. Normalmente el público conoce la decisión cuando se anuncia o cuando se ejecuta la acción. En este contexto, este ensayo buscará entender el proceso en los casos del voto mexicano en las ya mencionadas tres reuniones de la oEA. Para ello, recurrirá a fuentes primarias y secundarias donde hay información al respecto.

Afortunadamente para los interesados en el tema, algunos modelos analíticos ayudan a identificar y analizar el proceso informal de la toma de decisiones de la política exterior de un Estado. ${ }^{3}$ La teoría del juego del doble nivel, de Robert

${ }^{3}$ Los más representativos son los tres modelos de Graham Allison (actor racional, burocrático y organizacional), los tres niveles de análisis 
Putnam, ${ }^{4}$ es una opción muy útil para tal propósito. Este enfoque plantea que los gobiernos de los Estados tienen un dilema al tomar decisiones de política exterior. Además, deben considerar los intereses de los grupos internos y, al mismo tiempo, tienen que tomar en cuenta los factores externos para llegar a acuerdos. Para Putnam, el proceso debe, entonces, basarse a partir de dos criterios. El primero es que las acciones de política exterior han de buscar satisfacer a los grupos internos. El segundo, que es deseable que esas presiones no se conviertan en obstáculos para alcanzar acuerdos externos. En otras palabras, cualquier acción de política externa no debe poner en riesgo la cooperación con otros países. Por lo tanto, los gobiernos deben buscar opciones intermedias entre los intereses de ambas partes. De esta manera, los países deben dotar a su política exterior de una carga pragmática para alcanzar dicho objetivo.

Putnam plantea que, en las negociaciones internacionales, hay dos niveles. El nivel I es cuando un gobierno establece contacto con sus contrapartes para negociar un acuerdo (nivel externo). En el nivel II, el mismo gobierno consulta con los grupos de interés internos para lograr la ratificación del acuerdo (nivel interno). Es decir, las negociaciones internacionales pueden concebirse como un juego de doble nivel. "En el nivel nacional, los grupos persiguen sus intereses presionando al gobierno para que adopte políticas favorables, y los políticos buscan construir coaliciones entre esos grupos. En el nivel internacional, los gobiernos nacionales buscan maximizar su propia capacidad para satisfacer las presiones internas, minimizando al mismo tiempo las conse-

originalmente planteados por Kenneth Waltz (sistémico, estatal e individual) y el juego del doble nivel, de Robert Putnam. Véanse Graham Allison, Essence of decision, Explaining the Cuban Missile Crisis, EE.uu., Harper Collins, 1971 y Kenneth Waltz, The Man, the State, and the War. A Theoretical Analysis, Nueva York, Columbia University Press, 2001.

${ }^{4}$ Robert Putnam, "Diplomacy and Domestic Politics: The Logic of Two-Level Games”, en Peter Evans et al, Double-Edged Diplomacy, EE.uU., University of California Press, 1993. 
cuencias adversas de los acontecimientos internacionales". Además, Putnam plantea que la política exterior es como un juego de ajedrez, en dos tableros a la vez. Es decir, hay un tablero internacional y otro nacional. Entonces, el reto es jugar en dos pistas al mismo tiempo con el propósito de satisfacer a los grupos internos y lograr un acuerdo cooperativo con el actor externo. Ésta es la parte del juego que también se denomina "diplomacia del doble filo" (double-edged diplomacy, en inglés). El problema surge cuando los intereses de los grupos internos pueden ser distintos a los de la contraparte externa. Entonces, los gobiernos están obligados a buscar opciones que traten de dejar satisfechas a ambas partes. Este juego también requiere de dosis de pragmatismo para poder tener éxito.

Una de las principales aportaciones de Putnam al análisis del doble nivel es la noción de los "win-sets" (conjuntos ganadores). ${ }^{5}$ Para el autor, un "win-set" es la alternativa que resulta más favorable a ambas partes en una negociación en el nivel i y que contará con un amplio apoyo en el nivel iI. ${ }^{6}$ Es decir, es la opción que significa mayores beneficios mutuos al llegar a un acuerdo con un gobierno extranjero, pero que a la vez satisfaga los intereses de los grupos internos. Por ejemplo, en la negociación de un tratado comercial, un gobierno buscará mejores condiciones frente a su contraparte pero, al mismo tiempo, tratará de que el contenido del acuerdo beneficie a los sectores internos y de que la ratificación sea viable ante las instancias formales o informales correspondientes. En otras palabras, un win-set será mayor si el arreglo beneficia a la contraparte externa y a los grupos internos al mismo tiempo. Para Putnam, los determinantes del tamaño del win-set son básicamente tres: a) las preferencias y coaliciones en el nivel II; b) las instituciones

5 A lo largo del texto se utilizará el término "win-set" y no "conjuntos ganadores" para mayor claridad.

${ }^{6}$ Putman, op. cit. 
formales e informales en el nivel II, y c) las estrategias de los negociadores en el nivel I. ${ }^{7}$

En el primer punto, el tamaño del win-set depende de la distribución del poder, las preferencias y las coaliciones posibles entre los grupos comprendidos en el nivel II. Es decir, una decisión de política exterior puede depender de la correlación de fuerzas de los principales actores del sistema político, ya sean funcionarios de gobierno, congresistas, partidos políticos, sectores empresariales, organizaciones sociales u opinión pública. Asimismo, el curso de acción está determinado por las preferencias de política pública de cada uno de ellos. Finalmente, el proceso está condicionado por las posibles alianzas que puedan construir esos actores. Es decir, el tamaño del win-set aumentará si hay mayor consenso interno. En el segundo punto, el planteamiento de Putnam es que los procedimientos de ratificación afectan el tamaño del win-set. Por ejemplo, si el poder legislativo requiere dos tercios para ratificar un acuerdo, entonces el tamaño del win-set es más pequeño. Pero si solamente se necesita mayoría simple, entonces el win-set es de mayor tamaño. Incluso, el margen de maniobra puede aumentar frente a la contraparte si se argumenta que una cesión no podría ser aceptada por el aparato legislativo o la circunscripción interna. Además, no todos los acuerdos son ratificados de manera formal. Por ejemplo, la disciplina rígida de los partidos políticos incrementa el tamaño del win-set. Un gobierno tendrá mayor margen de maniobra si la probabilidad de que el acuerdo negociado se ratifique es elevada. Por el contrario, una débil disciplina partidaria reduce las posibilidades de cooperación internacional. En el último punto, el tamaño del win-set puede variar dependiendo de las estrategias que adopten los negociadores en el nivel I. Es decir, la dimensión puede ser mayor o menor en función de las opciones que se presenten en la negociación entre los actores internacionales. 
De manera particular, este artículo utilizará el juego del doble nivel como base teórica, pero incluirá dos nociones importantes. En primer lugar, no es sencillo aplicar en estos casos la lógica del doble nivel tal como lo plantea Putnam, debido a que no se trata de la negociación de un acuerdo comercial $^{8}$ y, por lo tanto, no es necesaria una ratificación legislativa. Además, el fuerte sistema presidencialista en México no exige consultar la decisión con los actores internos. Sin embargo, sí hay varios elementos que pueden aplicarse, especialmente el de los win-sets, debido a que el presidente ALM sí estaba interesado en satisfacer a los grupos internos y buscaba esquemas de cooperación con Estados Unidos y Cuba. Por lo tanto, el tamaño de los win-sets era importante al tomar la decisión.

En segundo lugar, en los casos de los votos de México en las tres reuniones de la oEA, no hubo dos tableros de juego, sino cuatro. Es decir, el presidente Adolfo López Mateos (ALM) tenía que jugar en cuatro pistas. La primera estaba representada por Estados Unidos, que buscaba aplicar sanciones a Cuba. La segunda era el régimen de Castro, que presionaba para que México aplicara sus principios tradicionales de no intervención y autodeterminación. La tercera pista estaba representada por los grupos nacionalistas de afiliación izquierdista que tenían simpatía con el comunismo cubano y demandaban la no intervención de Estados Unidos. Finalmente, el cuarto tablero era el grupo conservador, compuesto por los empresarios y la Iglesia, quienes demandaban al gobierno priista un voto en contra de Cuba para demostrar que México no defendía a los comunistas. En este

${ }^{8}$ En las negociaciones comerciales, existe evidencia de que el gobierno mexicano consulta con los empresarios durante el proceso de negociación, como fue el caso de la firma del TLCAN y el T-MEc. En ambos procesos, existió la figura del "cuarto de al lado". En la sala principal estaba la mesa en donde participaban los representantes del gobierno, pero al lado había una sala donde estaban los empresarios mexicanos. Cuando un tema se atoraba, los funcionarios consultaban el asunto con los representantes de organizaciones empresariales. 
contexto, Putnam reconoce que el nivel II (interno) puede dividirse en diferentes bandos con preferencias distintas. Entonces, el reto de este texto es analizar el tema desde esta sugerente perspectiva.

En resumen, la administración de López Mateos estaba frente a quienes demandaban una política exterior pragmática y a otros que exigían una de naturaleza principista. La existencia de cuatro tableros hacía más complicado el proceso de toma de decisiones. El reto era encontrar una fórmula que pudiera representar un amplio win-set para su administración. El uso del "pragmatismo principista" parecía una posible alternativa. Este concepto se refiere a cuando un gobierno adopta una política basada principalmente en intereses y busca arroparla con una faceta basada en principios normativos de política exterior, como la no intervención y la autodeterminación. Esto ocurre cuando un gobierno opta, en primer lugar, por beneficios económicos directos, sin alejarse de los principios tradicionales. Además, una acción podría entrar en esta clasificación cuando las consideraciones geopolíticas y de seguridad prevalecen, pero se busca llevar a cabo a través de una faceta principista. El argumento aquí es que en los votos en Punta del Este y en Washington, en 1962, ALM optó por un pragmatismo principista porque buscaba tener un beneficio económico, y la naturaleza de los temas era de seguridad y geopolítica. Según esta lógica, también puede existir un "principismo pragmático" en la política exterior. Es decir, en este caso, los principios prevalecen sobre el pragmatismo, pero en el fondo hay también intereses involucrados.

El planteamiento aquí es que, en el voto de 1964 en Washington, la administración de López Mateos recurrió al principismo pragmático porque puso el énfasis en los principios pero, al tomar esa decisión, el país también obtenía beneficios. En los siguientes párrafos, se desarrollará este argumento y se aportará evidencia empírica. 


\section{BREVE REVISIÓN DE LA LITERATURA EXISTENTE: LAS CONFUSIONES SOBRE LOS VOTOS}

En su momento, hubo mucho interés en el país y en el mundo por estudiar la posición de México en las tres reuniones de la oeA sobre el caso de Cuba. Como fue un evento que impactó a nivel mundial, tanto los diarios nacionales ${ }^{9}$ como los internacionales -especialmente en Estados Unidos, pero también en América Latina y Europa- siguieron con mucha atención el tema. Más adelante, surgió gran interés académico por explicarlo y analizarlo. Una de las principales obras al respecto fue el libro de Olga Pellicer, México y la Revolución cubana, publicado por El Colegio de México en 1972. El texto fue el trabajo académico más completo, profundo y analítico en su momento sobre la cuestión. Anteriormente, la revista Foro Internacional había publicado varios artículos que analizaban específicamente los votos de México en la oeA. ${ }^{10}$ En los años setenta, Mario Ojeda publicó importantes textos que aportaron factores explicativos a la política exterior de México, entre ellos su clásico libro de Alcances y límites de la política exterior de México. ${ }^{11}$ En ese tiempo, El Colegio de Mé-

${ }^{9}$ Por ejemplo, el tema de la viII Reunión de Consulta se llevó las principales columnas de los diarios de circulación nacional en México durante todos los días que duró la reunión (22 de enero al 31). Algo similar ocurrió en el caso de la reunión del Consejo de la oEA en octubre de 1962 y de la IX Reunión de Consulta de 1964.

${ }^{10}$ Antonio Gómez Robledo, "La crisis actual del sistema interamericano", Foro internacional, vol. III, 2 (10), octubre-diciembre, 1962, pp. 176208; Peggy Fenn, "México, la no intervención y la autodeterminación en el caso de Cuba", Foro Internacional, 4 (1 [13]), 1963; Olga Pellicer, "México en la oEA", Foro Internacional, 6 (2/3 [22-23]), 1965, pp. 290-293; María Elena Rodríguez, "Sobre la incomprensión a la postura mexicana frente a Cuba", Foro Internacional, vol. vi, 1 (21), julio-septiembre, 1965, pp. 121135; Olga Pellicer, "Los grupos patronales y la política exterior mexicana: las relaciones con la Revolución cubana", Foro internacional, 10 (1 [37]), 21, 1969.

${ }^{11}$ Mario Ojeda, "Las relaciones de México con el régimen revolucionario cubano", Foro Internacional, 14(4 [56]), 1974, pp. 474-506. Mario Ojeda, Alcances y límites de la política exterior de México, México, El Colegio 
xico y la revista Foro Internacional reflejaban un liderazgo en el estudio del tema.

En etapas más recientes aparecieron otras obras, como las de Ana Covarrubias, ${ }^{12}$ Leticia Bobadilla ${ }^{13}$ y Carlos Te1lo. ${ }^{14}$ Sus trabajos son de alta calidad y aportan elementos muy valiosos para entender el proceso de toma de decisiones de la política exterior de México frente a Cuba, con particular énfasis en los votos de México en la oEA. Las investigaciones de Covarrubias y Bobadilla se hicieron a partir de los archivos de la Secretaría de Relaciones Exteriores, dado que ya estaban los documentos disponibles. También existen dos obras fundamentales para poder entender el proceso de toma de decisiones de manera directa. La primera es el libro publicado por el mismo Manuel Tello Barraud, secretario de Relaciones Exteriores de ALM, intitulado México: una posición internacional, publicado en 1972. En la obra, el autor relata de primera mano varios detalles de la posición de México en los tres casos analizados en este artículo. La segunda es el libro de las memorias de Manuel

de México, 1976. Mario Ojeda, México y Cuba revolucionaria: cincuenta años de relación, México, El Colegio de México, 2008.

12 Ana Covarrubias, Mexican-Cuban Relations, 1959-1988, tesis de doctorado, Oxford University. "Cuba and Mexico: A Case for Mutual Nonintervention”, Cuban Studies, 26, 125, 1996; Historia de las relaciones internacionales de México, 1821-2010 (Caribe), México, sRe, 2011; "México y la revolución cubana: la independencia de un país dependiente", en Arturo C. Sotomayor Velázquez y Gustavo Vega Cánovas (coords.), El mundo desde México: ensayos de política internacional. Homenaje a Olga Pellicer, México, El Colegio de México, 2008, pp. 25-46.

13 Véanse Leticia Bobadilla, México y la OEA: los debates diplomáticos, 1959-1964, México, SRe, 2006; Leticia Bobadilla, "La exclusión de Cuba de la Organización de Estados Americanos: los desacuerdos diplomáticos entre México y Estados Unidos en 1962”, Istor: revista de historia internacional, año 9, núm. 33, 2008, pp. 58-76

${ }^{14}$ Carlos Tello, El fin de una amistad. La relación de México con la Revolución cubana, México, Planeta, 2005; Carlos Tello, "México frente a la expulsión de Cuba de la Organización de Estados Americanos", Cuadernos Americanos: Nueva Época, 2 (136), 2011. 
Tello Macías. ${ }^{15}$ Tello Macías era hijo del canciller y fungió como secretario de la delegación en la vir Reunión de Consulta. El texto contiene información relevante sobre lo ocurrido en el tema estudiado.

En Estados Unidos hubo también mucho interés de analizar el caso desde la perspectiva de la política exterior estadounidense en al marco de la Guerra Fría. Existen dos trabajos de tesis muy completos sobre el tema en particular. El primero es de Arthur Smith, titulado: Mexico and the Cuban Revolution: Foreign Policy Making in Mexico Under President Adolfo López Mateos (1958-1964). El segundo es el de Lawrence Koslow, Mexican Foreign Policy Decision-Making: the Mutual Adjustment of Needs and Independence, publicado en 1969. Ambos trabajos realizan una investigación hemerográfica muy amplia y analizan en detalle el proceso de toma de decisiones de la política exterior de la administración de ALM frente a los casos de Cuba en el marco de las reuniones de la oEA.

Por su parte, Renata Keller también ha hecho una contribución significativa al estudio del tema. En su libro, la autora consulta archivos desclasificados del gobierno de Estados Unidos para identificar el papel de México en el contexto de la confrontación entre ese país y Cuba. ${ }^{16}$ En un artículo, su planteamiento es que el apoyo de ALM a Castro en enero de 1962 fue tibio, y que las acciones fueron principalmente para "consumo interno". ${ }^{17}$ En otro texto, la autora plantea la importancia estratégica de la oeA para legitimar el bloqueo naval de JFK en la crisis de los misiles. ${ }^{18}$ Otro texto relevante es

15 Ana Covarrubias y Laura Muñoz, Manuel Tello: por sobre todas las cosas México, México, SRe, 2007.

${ }^{16}$ Renata Keller, Mexico's Cold War: Cuba, the United States, and the Legacy of the Mexican Revolution, Cambridge, University Press, 2015.

17 Renata Keller, "A foreign policy for domestic Consumption: Mexico's Lukewarm Defense of Castro, 1959-1969”, Latin American Research Review, vol. 47, núm. 2, 2012, pp. 100-119.

${ }^{18}$ Renata Keller, "Responsibility of the Great Ones': How the Organization of American States and the United Nations Helped Resolve the Cuban Missile Crisis", Journal of Latin American Studies (2019), pp. 1-22. 
el libro de William LeoGrande y Peter Kornbluh, titulado $D i$ plomacia encubierta con Cuba. Historia de las negociaciones secretas entre Washington y La Habana, publicado en 2015. En el texto, los autores revelan, a partir de archivos desclasificados, información que antes no se conocía. A esta altura era claro que, para poder entender el proceso de toma de decisiones de la política exterior de México frente a Cuba, había que estudiar las variables internas, así como las presiones de La Habana y Washington DC.

\section{La confusión sobre los votos}

En la literatura existente, hay una extendida confusión sobre los votos de México en esas tres reuniones, especialmente en la primera. ${ }^{19}$ Diversas fuentes señalan que el gobierno mexicano votó en contra de la expulsión de Cuba de la oeA en enero de 1962, cuando en realidad se abstuvo. Incluso en algunos casos no hay claridad sobre la existencia de las tres reuniones y poco se menciona en la literatura que México votó a favor de la posición de Estados Unidos cuando Washington propuso, en la oEA, una resolución para exigir el retiro de los misiles de Cuba en octubre de 1962. En el imaginario colectivo, existe información del rechazo de México a romper relaciones con Cuba en julio de 1964. Tampoco hay claridad sobre los temas que se trataron en las reuniones. Por ejem-

${ }^{19}$ Por ejemplo, en un examen de evaluación nacional se preguntaba sobre el voto emitido por México en la viII Reunión de Consulta de Ministros de la oEA en enero de 1962. La respuesta correcta, según el examen, era que México había votado en contra, cuando en realidad el voto fue de abstención. Incluso, la confusión es muy reciente. Por ejemplo, los siguientes artículos periodísticos plantean que el voto fue en contra: Rafael de la Garza, "De Cuba a Venezuela: la decadencia de la diplomacia mexicana”, La Jornada, 5 de abril de 2017, http://jornadaveracruz.com. mx/Post.aspx?id=170405_072846_428; Roberto Rock, "El solitario de Montevideo", El Universal, 8 de marzo de 2019, https://www.eluniversal. com.mx/columna/roberto-rock-l/nacion/el-solitario-de-montevideo. 
plo, un documento de la SRE señala: "en julio de 1964, cuando la Ix Reunión de Consulta de Ministros de Relaciones Exteriores de la Organización de Estados Americanos (OEA) votó la resolución que excluyó a Cuba del Sistema Interamericano, solamente Bolivia, Brasil, Chile, Uruguay y México mantuvieron relaciones con la isla". ${ }^{20} \mathrm{El}$ dato es inexacto porque la reunión de 1964 no fue para la "exclusión" de Cuba. Además, Brasil ya había roto relaciones con la isla desde antes, luego de un golpe de Estado en ese país.

La confusión puede explicarse por diversas razones. La primera es que no hay claridad de que hubo dos reuniones de consulta: una en 1962 y otra en 1964. En la primera, el planteamiento era "excluir" a Cuba de la oEA. En la segunda, el objetivo era el "rompimiento" de relaciones diplomáticas con Castro. Como en la de 1964 el voto fue en contra, entonces existe la creencia colectiva de que México votó en contra de la exclusión de Cuba de la oeA. La segunda razón es que, desde junio de 1961, Colombia había convocado a la viri Reunión de Consulta de la oEA, alegando que se tenía que aplicar el artículo 6 del Tratado Interamericano de Asistencia Recíproca (TIAR), porque el régimen comunista de Castro estaba violentando el clima de la región. En la reunión del Consejo de la oEA, México votó en contra de la propuesta porque no existía evidencia de un acto de violencia por parte de Cuba contra algún miembro de la oEA. Tal vez la confusión surge porque, efectivamente, México votó en contra de la propuesta de llevar a cabo dicha reunión. Sin embargo, a pesar del voto en contra, la reunión se llevó a cabo en enero de 1962 en Punta del Este, Uruguay. Ya en ésta, se propuso la exclusión de Cuba.

La tercera razón es que en la viri Reunión los asistentes propusieron varias resoluciones. Sin embargo, la principal

${ }^{20}$ Véase el documento: Secretaría de Relaciones Exteriores, "Relanzamiento de la relación México-Cuba", https:/ /www.gob.mx/sre/documentos/68206. Era muy notable la confusión entre académicos, periodistas y funcionarios de gobierno. 
era el punto vi, que proponía la exclusión de Cuba del organismo. Específicamente en esta resolución, el voto de México fue de abstención, según las actas oficiales, las notas periodísticas de la época y los archivos de la SRE. Otra razón de la vaguedad es que hay fuentes que resultan ambiguas. Por ejemplo, algunas afirman que México "no apoyó” la expulsión de Cuba. Técnicamente están en lo correcto porque una abstención implica no "avalar" la exclusión. Sin embargo, dejan de manera "implícita" la idea de que el voto fue en contra, lo que se suma a la confusión.

De 50 fuentes bibliográficas y hemerográficas consultadas, 13 señalan explícitamente que México votó en contra de la resolución de expulsar a Cuba de la oEA en la VIII RGMRE de este organismo. Es decir, 13 fuentes son erróneas. Por lo tanto, los lectores tendrán una información incorrecta. A su vez, 13 señalan implícitamente que México "no apoyó" la propuesta de expulsar a Cuba. Es decir, hay 26 fuentes imprecisas. Solamente 24 fuentes señalan atinadamente que el voto fue de abstención. Es decir, cuantitativa y comparativamente, son menores las fuentes que están en lo correcto.

En las dos siguientes reuniones, 18 fuentes consultadas no señalan el voto de México en la reunión que trató el retiro de los misiles soviéticos de Cuba y seis señalan explícitamente el voto a favor. Es decir, hay pocos autores que conocen con certeza esta acción, razón por la cual existe también una extendida creencia de que México apoyó casi incondicionalmente a Cuba en aquella etapa, cuando lo cierto es que, en algunas ocasiones, el gobierno de ALM le dio la espalda al régimen de Castro. También hay una confusión respecto a la Ix Reunión de Consulta. Varias fuentes señalan que México fue el único país que votó en contra de la propuesta de romper relaciones diplomáticas con Cuba, pero Bolivia, Chile y Uruguay también votaron así. Lo cierto es que México fue el "único" que no rompió relaciones con Cuba a pesar de que se aprobó la resolución. Es decir, el país violó el derecho internacional al no acatar una resolución aprobada por un organismo internacional. De 21 fuentes consultadas, 15 son 
correctas al señalar el voto en contra. Hay cinco fuentes que, manera implícita, reportan el voto en contra y una que implícitamente plantea un voto de abstención. No hay ninguna fuente que marque explícitamente un voto de abstención o a favor (véase cuadro 1).

\section{CuAdro 1}

Reportes de las fuentes respecto a los votos

\begin{tabular}{|c|c|c|c|c|}
\hline & $\begin{array}{c}\text { Reportan } \\
\text { explícitamente } \\
\text { voto de abstención }\end{array}$ & $\begin{array}{c}\text { Reportan } \\
\text { explicitamente } \\
\text { voto en contra }\end{array}$ & $\begin{array}{c}\text { Reportan } \\
\text { implicitamente } \\
\text { voto en contra }\end{array}$ & Total \\
\hline \multirow[t]{2}{*}{$\begin{array}{l}\text { VIII RCMRE-OEA, } \\
\text { enero de 1962, Punta } \\
\text { del Este, Uruguay } \\
\text { Exclusión de } \\
\text { Cuba de la OEA }\end{array}$} & 24 & 13 & 13 & 50 \\
\hline & $\begin{array}{c}\text { Reportan } \\
\text { explícitamente el } \\
\text { voto a favor }\end{array}$ & $\begin{array}{l}\text { No reportan } \\
\quad \text { el voto }\end{array}$ & $\begin{array}{c}\text { Reportan voto } \\
\text { en contra o } \\
\text { abstención }\end{array}$ & \\
\hline \multirow{2}{*}{$\begin{array}{l}\text { Consejo de la OEA, } \\
\text { octubre de } 1962, \\
\text { Washington, D.C., } \\
\text { Crisis de los misiles }\end{array}$} & 6 & 18 & 0 & 24 \\
\hline & $\begin{array}{c}\text { Reportan } \\
\text { explicitamente el } \\
\text { voto en contra }\end{array}$ & $\begin{array}{c}\text { Reportan } \\
\text { implícitamente el } \\
\text { voto en contra }\end{array}$ & $\begin{array}{c}\text { Reportan } \\
\text { implícitamente el } \\
\text { voto de abstención }\end{array}$ & \\
\hline $\begin{array}{l}\text { IX RCMRE-OEA, } \\
\text { julio de 1964, } \\
\text { Washington, D.c. } \\
\text { Rompimiento de } \\
\text { relaciones } \\
\text { diplomáticas } \\
\text { con Cuba }\end{array}$ & 15 & 5 & 1 & 21 \\
\hline
\end{tabular}

Fuente: elaboración propia con información de las fuentes consultadas. 
Desafortunadamente, las fuentes que reportan de manera precisa los votos son principalmente extranjeras, en especial de Estados Unidos y algunas cubanas. Todas las noticias periodísticas se consultaron esos días publican los datos de manera correcta. ${ }^{21}$ En el caso de las fuentes mexicanas, las que consultaron archivos y fuentes de primera mano son, en general, acertadas.

Una pregunta lógica que puede surgir es la siguiente: ¿si ya existen muchas fuentes sobre el tema, entonces, por qué escribir un nuevo artículo? La respuesta tiene varios argumentos. En primer lugar, es preciso aclarar de manera fehaciente, con base en fuentes primarias, el sentido del voto de México en esos tres casos. Esto ayudará a que los interesados en el tema tengan la información correcta. En segundo lugar, el objetivo de este trabajo es explicar los tres votos de manera conjunta para entender por qué hay uno de abstención, en enero de 1962, otro a favor nueve meses después y uno en contra dos años después, cuyo tema era, con sus respectivos matices, similar. Muy pocas fuentes lo han hecho desde esta perspectiva. La tercera razón es que el texto se enfoca, de manera particular, en el proceso de toma de decisiones de la política exterior de México. Es decir, la idea es identificar a los actores y los factores externos e internos que influyeron en la diplomacia adoptada por México en los tres casos. Tampoco hay muchas fuentes que así lo hagan. Lo novedoso de esta perspectiva es que se usa el concepto de "pragmatismo principista" para describir dicho proceso. En cuarto lugar, el acercamiento al tema se hace desde una teoría concreta de la política exterior, como el juego del doble nivel, de Robert Putnam. Inclusive, una de las aportaciones novedosas es que el artículo recurre a la teoría de los win-sets para explicar los votos de México en las tres reuniones de la

${ }^{21}$ Se consultaron periódicos estadounidenses y mexicanos (The New York Times, The Washington Post, Excelsior, El Universal, entre otros). Tal vez, la dificultad para acceder a los periódicos de la época sea una razón que explica la variación de la información. 
OEA, rasgo que le imprime un elemento novedoso y original, dado que ningún otro autor lo ha hecho.

Finalmente, la política exterior de México hacia Cuba es un tema siempre vigente, por lo tanto, este trabajo no es un ejercicio meramente histórico. Todavía en las dos primeras décadas del siglo Xxi se discute en redes sociales y en medios de comunicación. En especial cuando el entonces presidente Vicente Fox generó una crisis diplomática con Cuba en 2002 y otra en 2004. Además, con la llegada a la presidencia en 2018 del candidato de izquierda, Andrés Manuel López Obrador (AMLO), el tema de la política exterior frente a gobiernos de naturaleza socialista retomó un nuevo interés, en especial por la posición de México frente al caso de Venezuela y el otorgamiento del asilo político a Evo Morales en 2019. La lucha entre los grupos nacionalistas y conservadores, así como la presión de Estados Unidos, por una parte, y de la izquierda latinoamericanista por la otra, han dado lugar al resurgimiento de temas de esta índole. Por lo tanto, este trabajo puede ser útil y aportar para entender el proceso de toma de decisiones de política exterior de la administración en turno o de las siguientes.

\section{Los votos de México en LA VIII-RCMRE de LA OEA en Punta del Este, Uruguay, 1962: EL Juego DE LOS CUATRO TABLEROS}

Con el triunfo de la Revolución de Fidel Castro en Cuba en 1959 y el apoyo soviético a la isla, la Guerra Fría llegó al continente americano. En consecuencia, las relaciones de Washington con la isla se tornaron tensas. En ese mismo año, la situación interna en México era complicada desde el punto de vista social y político. Por un lado, varios gremios de trabajadores habían iniciado huelgas para exigir mejores condiciones e independencia en la afiliación sindical. Por lo tanto, había mucha efervescencia política y descontento social. Por otro lado, el triunfo de Castro motivó la creación de 
nuevas organizaciones políticas, como el Movimiento de Liberación Nacional (MLN), que buscaba convertirse en una coalición que aglutinara a los diferentes grupos de izquierda. Un líder de este movimiento fue el expresidente Lázaro Cárdenas, quien gozaba de influencia política en esa época. Además, la economía de México tuvo algunos desajustes al principio del sexenio, con reducción de inversiones, salida de capitales y un crecimiento del PIB menor en comparación con años anteriores.

Estos elementos estuvieron presentes en las primeras posturas que el gobierno de Adolfo López Mateos adoptó frente a Cuba. Al principio, el mismo presidente mostró simpatía y comparó la Revolución cubana con la de México de 1910. Según ALM, ambos movimientos habían sido nacionalistas y buscaban reivindicar demandas sociales. Incluso, el presidente se había declarado de "extrema izquierda" dentro de la Constitución. ${ }^{22}$ En este contexto, ALM invitó a Osvaldo Dorticós, el presidente cubano, a realizar una visita a México en 1960. Los objetivos de ALM eran congraciarse con la izquierda y mandar una señal a Estados Unidos de autonomía en materia de política exterior. Las iniciativas mexicanas de apoyo a Cuba generaron nerviosismo en Estados Unidos y entre los grupos conservadores en México.

En abril de 1961, la cia apoyó una invasión a Bahía de Cochinos. En México se organizaron protestas masivas que apoyaban a Cuba y exigían la no intervención estadounidense. Incluso el general Cárdenas voló en un avión privado a Cuba desde el aeropuerto de la Ciudad de México para defender a su pueblo de la invasión. Sin embargo, por órdenes de ALM el avión no despegó. ${ }^{23}$ En público, la administración de López Mateos condenó el ataque y defendió los principios de no intervención y solución pacífica de controversias.

22 Olga Pellicer, "La revolución cubana en México", Foro Internacional, vol. viII, 4 (32) abril-junio, 1968, p. 368.

${ }^{23}$ Renata Keller, Mexico's Cold War. Cuba, the United States, and the Legacy of the Mexican Revolution, Cambridge, University Press, 2015, p. I. 
Sin embargo, de acuerdo con archivos desclasificados, el gobierno mexicano apoyó la invasión al entregar 50000 galones de gasolina a los exiliados cubanos ${ }^{24}$ y ofreció, en secreto, la isla de Cozumel en caso de que los aviones estadounidenses tuvieran necesidad de usar una pista en caso de guerra. ${ }^{25}$ Estas dos acciones mostraban el doble juego de López Mateos hacia Cuba. Por un lado, el país mostraba en público su rechazo a la invasión y, en privado, exponía el alineamiento hacia Estados Unidos. En la práctica, México se inclinaba a apoyar a Washington y a estar en contra de Castro. Para ello, tenía que recurrir al pragmatismo principista.

Desde junio de 1961, Colombia había propuesto ante el Consejo de la oEA celebrar una reunión de consulta de ministros de relaciones exteriores para deliberar sobre el caso cubano. El argumento era que Cuba estaba violando el artículo 6 del TIAR y que el gobierno comunista de Castro representaba una amenaza para la paz en la región. El Consejo había estado posponiendo la reunión, pero el 2 de diciembre de ese mismo año Fidel Castro declaró que su movimiento era "marxista-leninista". El anuncio tuvo impactos muy significativos en el contexto mundial y regional. Dos días después, y como consecuencia de la declaración, el Consejo de la oEA se reunió para discutir la propuesta de Colombia. El representante de México argumentó que el artículo del TIAR no era relevante porque en ningún momento Cuba había atacado a un miembro de la alianza. ${ }^{26}$ Con esta lógica, México votó en contra de la convocatoria. ${ }^{27}$ Sin embargo, otros países votaron a

${ }^{24}$ Ver Jefferson Morley, Our Man in Mexico: Winston Scott and the Hidden History of the CIA, Kansas, University Press of Kansas, 2008, p. 108.

${ }^{25}$ William LeoGrande y Peter Kornbluh, Diplomacia encubierta con Cuba. Historia de las negociaciones secretas entre Washington y La Habana, México, FCE, 2015, p. 132.

${ }^{26}$ Edward Jamison, "Cuba and the Inter-American System: Exclusion of the Castro Regime from the Organization of American States", The Americas, vol. 36, núm. 3 (enero de 1980), p. 330.

${ }^{27} \mathrm{El}$ voto en contra en el Consejo puso nerviosos a Estados Unidos y a los grupos conservadores en México. El gobierno de ALM recibió críticas porque estaba apoyando un gobierno comunista. 
favor y, por lo tanto, el Consejo convocó a la viII reunión de Consulta que se celebraría a partir del 22 enero de 1962 en Punta del Este, Uruguay. Los temas principales eran la aplicación del TIAR, iniciar un bloqueo a la isla, imponer sanciones a Cuba, rechazar el comunismo en la región, y excluir a Cuba de la oEA. ${ }^{28}$ La convocatoria no le gustó a Castro.

En este contexto, la administración de ALM tenía que tomar una decisión frente a los temas de la reunión. La situación interna y los factores externos pesaban de manera significativa. Por un lado, había una amplia coalición de grupos nacionalistas y partidos de izquierda, cuyas preferencias eran la no intervención de Estados Unidos en la isla. Además, los win-sets para ALM eran, en el nivel II, apaciguar a los grupos nacionalistas y en el nivel I, mostrar independencia frente a Washington y aplicar los principios de no intervención y autodeterminación. Por otro lado, la derecha y los sectores económicos habían construido también una coalición informal y estaban nerviosos por la actitud pro Castro del gobierno. Asimismo, el win-set para Washington era aplicar sanciones a Cuba en el marco de su lucha contra el comunismo y para ello necesitaba el apoyo de México. Además, ALM no quería mostrarse a favor del comunismo, pues días antes Fidel Castro había hecho el anuncio de que su gobierno era marxista-leninista. En este contexto, su administración tuvo que empezar a jugar en los cuatro tableros para tomar una decisión. El objetivo era buscar una alternativa que permitiera generar un amplio win-set que pudiera, en la medida de lo posible, satisfacer los cuatro tableros al mismo tiempo.

${ }^{28} \mathrm{El}$ acta de la reunión se encuentra en el documento: "Informe sobre la Octava Reunión de Consulta de Ministros de Relaciones Exteriores que presenta el secretario general de la Delegación de México, Manuel Tello Macías", disponible en el expediente del Archivo de la Secretaría de Relaciones Exteriores, III-5660-11 1A. 
Los cuatro tableros y los win-sets: preferencias, coaliciones, instituciones y estrategias

El tablero 1 del nivel I estaba compuesto por los actores externos que tenían interés en que México asumiera una posición principista y de apoyo a la isla. En primer lugar, hay que incluir a Fidel Castro, primer ministro de Cuba. Obviamente el win-set para Castro estaba representado por la no intervención de Estados Unidos y la no aplicación de sanciones. Por otro lado, para esos momentos existía el temor de que Castro pudiera exportar la Revolución cubana a otros países de la región. Su régimen apoyaba a partidos comunistas e incluso ayudaba a movimientos rebeldes. La preferencia de López Mateos era apegarse a los principios para, así, evitar que Castro pudiera apoyar a los movimientos comunistas en México. Otro actor importante era el presidente cubano, Osvaldo Dorticós. No tenía un papel relevante en la política en Cuba, pero acudió como jefe de la delegación a Punta del Este y tuvo contactos con el secretario Manuel Tello para conversar sobre el tema. El acercamiento con Tello fue una de sus estrategias, dado que México era considerado un jugador clave. Otros actores relevantes eran el ministro de Relaciones Exteriores, Raúl Roa, y el embajador de Cuba en México, José Antonio Portuondo, quienes también buscaron que México adoptara una posición favorable a la isla.

Como estrategia en el nivel I, el subsecretario de Relaciones Exteriores de Cuba, Carlos Olivares, visitó al presidente ALM en diciembre de 1961 para informarle que haría una gira por varios países latinoamericanos para conocer "la actitud" de sus ministros de Relaciones Exteriores respecto a la reunión en Punta del Este. Incluso Olivares se ofreció a regresar a México al terminar su gira para informar los resultados de su gestión. ${ }^{29}$ Unos días antes el diplomático se reunió con ALm y Manuel Tello para comentar el resultado de su

${ }^{29}$ Manuel Tello, México, Una posición internacional, México, Joaquín Mortiz, 1972. 
visita. Era claro que Cuba consideraba a México como un líder regional y quería estar al tanto de la posición que asumiría este país.

También México recibió presión de la izquierda latinoamericanista, encabezada por el chileno Salvador Allende, entre otros. Su posición en conjunto era la no interferencia de Estados Unidos y evitar las sanciones a Cuba. Otro grupo de países fueron los denominados "soft-line", que estaban en contra de sanciones a Cuba, aunque tampoco eran simpatizantes de la naturaleza marxista-leninista del gobierno de Cuba. Estos países también tenían problemas internos similares a México y por eso también buscaban una posición que pudiera ser conveniente para todos. Los países más representativos eran Brasil, Argentina, Chile, Ecuador y Bolivia. Como estrategia en el nivel I, buscaban generar consenso en la reunión.

En el tablero 2 del nivel i estaban los actores externos que exigían que México adoptara una posición pragmática y asumiera una actitud anticomunista. El grupo estaba encabezado por el presidente Kennedy, quien tenía interés en aplicar sanciones a Cuba tras la declaración de Castro del 2 de diciembre y de las nacionalizaciones de las empresas estadounidenses. El principal interés de Kennedy era evitar que la Unión Soviética apoyara al régimen de Castro, porque ello amenazaba su seguridad nacional. Antes de la reunión, la SRE informó que Kennedy visitaría México durante el primer semestre de 1962. Este anuncio fue importante en el proceso de toma de decisiones, porque podía inclinar la balanza hacia una posición más pragmática; es decir, representaba un win-set para México. Además, ALm estaba muy interesado en acceder a recursos de la Alianza para el Progreso (ALPRo), la cual había sido la respuesta de la llegada del comunismo a la región y de las intenciones de Castro de exportar su revolución a otros países latinoamericanos. En este esquema de cooperación, el gobierno de Estados Unidos estaba dispuesto a financiar a los gobiernos latinoamericanos para fortalecerlos y evitar la llegada de grupos comunistas al poder, una especie de Plan Marshall para América Latina. ALm temía que 
si México se inclinaba demasiado a defender a Cuba, entonces el Congreso de Estados Unidos no vería con buenos ojos enviar dinero a México. Además, Alm quería resolver dos asuntos bilaterales pendientes: el diferendo territorial con el Chamizal y la salinidad del Río Colorado. Una posición totalmente antiestadounidense pondría en riesgo las aspiraciones de México y disminuiría su win-set respecto a Estados Unidos en el nivel I.

Otros actores en el tablero 2 del nivel I eran los inversionistas estadounidenses. Si bien ellos no presionaban de manera directa a México, era claro que no invertirían en el país si su gobierno mostraba una fuerte simpatía al comunista en Cuba. Esta variable también estaba en la mente del canciller Tello durante las sesiones de la reunión en Punta del Este y representaba un importante win-set. Por otra parte, ALM personalmente estaba interesado en la prensa extranjera. Tenía control sobre los medios nacionales, pero no sobre los foráneos. Si los periódicos internacionales publicaban notas negativas, entonces los congresistas estadounidenses podrían poner obstáculos a la ALPRO y los inversionistas tendrían dudas de llevar sus capitales al país. Hubo una nota en The New York Times que tachaba a México de apoyar al gobierno de Cuba. La evidencia refleja que a ALm le preocupaban ese tipo de notas. ${ }^{30}$ Finalmente, los países del "hard-line", Colombia, Perú y algunos de Centroamérica exigían la aplicación de sanciones a Cuba y presionaban a México para votar por su causa.

En el tablero 3 del nivel II estaban ubicados los grupos internos pro Cuba, que estaban a favor de la defensa del régimen de Castro y, por lo tanto, impulsaban una postura prin-

${ }^{30}$ Gran parte de los archivos consultados en la SRE contenían notas periodísticas de diferentes países sobre la posición de México en Punta del Este. Incluso había análisis que interpretaban si las notas eran favorables a México o no. Era claro que había una instrucción específica de que las embajadas mexicanas enviaran esas notas periodísticas y, por la evidencia en los archivos, ese tipo de información llegaba a la oficina del presidente López Mateos. Véase el expediente (AHSRE), III-5660-11 1A. 
cipista. Había diferentes tipos de organizaciones. Por un lado, la extrema izquierda, que era poco flexible en su posición. Pero también existía la izquierda oficialista, dirigida principalmente por Lázaro Cárdenas. El expresidente había tenido una influencia importante en la creación del MNL y era uno de los que encabezaban la defensa de Cuba. López Mateos estaba inconforme con el papel que parecía asumir Cárdenas porque, en principio, rompía la regla no escrita del sistema político mexicano de que un expresidente no se metía en la política de una nueva administración. Incluso, el expresidente amenazó con salirse del PRI para fundar un nuevo partido debido a las presiones del presidente López Mateos. Además, la posición pro Castro de Cárdenas generaba problemas con la derecha y con Estados Unidos. Para aislar a Cárdenas y modificar el equilibrio de poder en el nivel II, ALM le ofreció en diciembre de 1961 un puesto en el gobierno como consejero de la Cuenca del Río Balsas. El expresidente aceptó la oferta debido a que las presiones aumentaron y su margen de movilidad se había reducido. Ya neutralizado, Cárdenas tuvo un perfil más bajo en el periodo previo a la reunión en Punta del Este. ${ }^{31}$

Como ya se mencionó, el MLN apareció después de la Revolución cubana. Este movimiento surgió de la Conferencia por la Soberanía Nacional, la Emancipación y la Paz que encabezaba Lázaro Cárdenas. Varios intelectuales y partidos de izquierda se integraron al movimiento, como el Partido Popular Socialista (PPS), cuyo dirigente era Vicente Lombardo Toledano, y el Partido Comunista Mexicano (PCM). El MLN tuvo una influencia importante en 1961 y se convirtió en el principal grupo de presión que demandaba la no intervención de Estados Unidos en Cuba. El movimiento abanderó varias marchas y campañas de cartas y telegramas para plantear sus preferencias en el nivel II. Sin embargo, antes de la reunión de Punta del Este, ALM había amenazado con repri-

31 Olga Pellicer, "La revolución cubana en México", Foro Internacional, vol. viII, 4 (32) abril-junio, 1968. 
mir cualquier marcha procomunista en el país, mostrando un adelanto a una posición anticomunista durante la reunión. ${ }^{32}$ Más adelante, el MLN empezó a desarticularse antes de la reunión de Punta del Este. El PPs y el PCM se salieron por diferencias en la organización. La neutralización de Cárdenas y la desarticulación del MLN debilitaron a la izquierda en su conjunto y modificaron el equilibrio de poder a favor del tablero 4. Es decir, antes de la viıI reunión de consulta, la izquierda ya no representaba un grupo de presión unido ni fortalecido. En palabras de la lógica del win-set de Putnam, la coalición en el tablero 3 del nivel in se había debilitado.

En este mismo tablero también hay que incluir a los estudiantes, intelectuales y simpatizantes de la Revolución cubana. Varios grupos de alumnos se organizaron para defender el movimiento revolucionario. En la época, también surgió el Frente Estudiantil en Defensa de la Revolución cubana, compuesto por estudiantes de diversas universidades del país.

También existían otros grupos internos que no tenían mucha participación en el proceso de toma de decisiones, pero se inclinaban por una política principista. En particular, el Congreso mexicano tenía interés en el tema, pero estaba supeditado al Ejecutivo. Es decir, debido el fuerte presidencialismo, los legisladores no representaban un contrapeso real frente al mandatario en estos asuntos y no constituían un verdadero grupo de presión. Esta característica representaba una ventaja dentro de la noción de los win-sets de Putnam, porque había una fuerte disciplina partidaria. Es decir, cualquier decisión sería apoyada por el Congreso porque el presidente tenía la mayoría de su partido en ambas cámaras legislativas. En concreto, como en el discurso el presidente defendía el principio de no intervención, entonces los diputados y senadores se alineaban a la posición oficialista. En este contexto, ambas cámaras defendían abiertamente una posición legalista para la cita en Punta del Este. Incluso, en la

32 Joe Foweraker y Ann Craig, Popular movements and political change in Mexico, Boulder, Rienner, 1990. 
delegación de México que acudió a la reunión había algunos legisladores para servir de ratificación informal en el marco del juego del doble nivel. Antes de que Manuel Tello partiera a Punta del Este, en una ceremonia de despedida, algunos legisladores defendieron los principios de política exterior de México. ${ }^{33}$

Otro actor relevante era el partido en el poder. El PRI defendía abiertamente al presidente y pugnaba por una política basada en principios. La mayoría de sus miembros eran nacionalistas y estaba a favor de la defensa de Cuba; los más prominentes de la familia revolucionaria eran los expresidentes vivos. En un acto de unidad y para modificar las coaliciones en el nivel II, ALM nombró en diciembre de 1961 a cada uno de ellos en un puesto administrativo de bajo perfil. La decisión tuvo toda la intención de fortalecer el win-set del presidente en el nivel iI y mostrar unidad en la política exterior frente al caso cubano. ${ }^{34}$ Solamente Cárdenas apoyaba Cuba. Los demás eran anticomunistas.

Un actor clave en este proceso fue la burocracia de la Secretaría de Relaciones Exteriores (SRE) que incluye al Servicio Exterior Mexicano (SEM). El presidente tomaba las decisiones, pero ellos se encargaban de ponerlas en funcionamiento. Normalmente los miembros del SEM habían sido institucionales y defendían la aplicación de los principios. Incluso, el mismo canciller Manuel Tello mostraba en público su preferencia de tomar una decisión basada en los principios, pero era claro que el secretario cumpliría con las instrucciones del presidente.

Por otra parte, los sindicatos oficialistas se alineaban al partido y al presidente. Varios sectores laborales mostraron

33 "Palabras pronunciadas por el Senador Lic. Antonio Mena Brito. Secretario de la Gran Comisión, ante el señor Secretario de Relaciones Exteriores, antes de su partida a la Conferencia de Punta del Este, en representación de un grupo de Senadores", Archivo SRE, SPR-413-1.

${ }^{34}$ Arthur Smith, Mexico and the Cuban Revolution: Foreign Policy Making in Mexico Under President Adolfo López Mateos (1958-1964), tesis doctoral, Cornell University, 1970, p. 146. 
su apoyo a través de miles de cartas y de telegramas que llegaron al Palacio Nacional. Muchas de las comunicaciones apoyaban una posición "eminentemente jurídica" y la defensa de la "no intervención”. Para el presidente, esa posición representaba un win-set en el nivel II, porque era importante mantener el apoyo de estos sectores y, por lo tanto, era necesario adoptar una decisión acorde a sus preferencias. En esa época, una política independiente frente a Estados Unidos ayudaba a la élite partidista a generar consenso interno y a mantenerse en el poder. En ese entonces, lo medios de comunicación también eran oficialistas y no reflejaban independencia. El PRI tenía un control muy estricto de lo que publicaba la prensa. Sin embargo, en general los medios se inclinaban hacia la defensa de los principios. A pesar del control gubernamental sobre los medios, el presidente era cuidadoso en sus declaraciones.

Por otro lado, en el tablero 4 del nivel ir estaban los grupos conservadores. También aquí había una coalición importante. Por un lado, dentro del PRI existía una derecha oficialista encabezada por Miguel Alemán. El expresidente estaba ligado a las corporaciones empresariales de México y dirigía una campaña anticomunista en el país. Las organizaciones empresariales, como la Coparmex, consideraban el régimen de Castro "un peligro" para toda América. ${ }^{35}$ El PAN también promovió el voto a favor de las sanciones a Cuba y demandaba que ALM mostrara una faceta anticomunista. La Iglesia también tuvo un papel importante. Por ejemplo, el Centro de Unidad Democrática hacía labor política y planteaba el comunismo como una amenaza. A diferencia de las organizaciones de izquierda, el grupo conservador estaba fortalecido y mostraba unidad. La derecha incluso contaba con recursos financieros para apoyar campañas en los principales periódicos a partir de inserciones pagadas. Estos elementos representaban una fuerte presión para el gobierno.

35 "Gran peligro para toda América es el régimen de Cuba, reitera la patronal”, El Universal, 23 de enero de 1962, p. 1. 


\section{Cuadro 2 \\ Los 4 tableros del juego}

\begin{tabular}{|c|c|c|}
\hline & Los actores externos (nivel I) & Los grupos internos (nivel II) \\
\hline & Tablero 1 & Tablero 3 \\
\hline \multirow[t]{2}{*}{$\begin{array}{l}\text { De izquierda } \\
\text { (principismo) }\end{array}$} & $\begin{array}{l}\text { Fidel Castro, primer ministro de Cuba } \\
\text { Osvaldo Dorticós, presidente de Cuba } \\
\text { Raúl Roa, ministro de Relaciones } \\
\text { Exteriores de Cuba } \\
\text { Carlos Olivares, subsecretario de } \\
\text { Relaciones Exteriores de Cuba } \\
\text { José Antonio Portuondo, embajador } \\
\text { de Cuba en México } \\
\text { Izquierda latinoamericana, Salvador } \\
\text { Allende } \\
\text { Países latinoamericanos (Brasil, } \\
\text { Argentina, Chile, Ecuador, Bolivia) } \\
\text { (soft-line) } \\
\end{array}$ & $\begin{array}{l}\text { La izquierda oficialista (Lázaro } \\
\text { Cárdenas) } \\
\text { El Movimiento Nacional de } \\
\text { Liberación (MNL) } \\
\text { Los partidos políticos (PPS, PCM) } \\
\text { Intelectuales de izquierda } \\
\text { Grupos estudiantiles } \\
\text { Sindicatos disidentes } \\
\text { Amigos de Cuba } \\
\text { El Congreso mexicano y el PRI } \\
\text { El sEm y la burocracia de la SRE } \\
\text { Sindicatos oficialistas y medios } \\
\text { de comunicación } \\
\end{array}$ \\
\hline & Tablero 2 & Tablero 4 \\
\hline $\begin{array}{c}\text { Derecha } \\
\text { anticomunista } \\
\text { (pragmatismo) }\end{array}$ & $\begin{array}{l}\text { J. F. Kennedy, presidente de EE.UU. } \\
\text { Dean Rusk, secretario de Estado } \\
\text { Thomas Mann, embajador de EE.UU. } \\
\text { en México } \\
\text { Congreso de EE.UU. } \\
\text { Inversionistas externos } \\
\text { Medios de comunicación de EE.UU. } \\
\text { Países latinoamericanos (Colombia, } \\
\text { Perú) (hard line) }\end{array}$ & $\begin{array}{l}\text { La derecha oficialista (Miguel } \\
\text { Alemán) } \\
\text { Asociaciones empresariales } \\
\quad \text { (Coparmex, Concanaco) } \\
\text { Los empresarios } \\
\text { Partidos políticos (PAN) } \\
\text { La Iglesia } \\
\text { Centro Unidad Democrática } \\
\text { Secretarías de Hacienda } \\
\text { Secretaría de Industria y } \\
\text { Comercio }\end{array}$ \\
\hline
\end{tabular}

Fuente: elaboración propia.

La administración de ALM se preocupaba porque la economía del país a finales de 1961 presentaba algunos desajustes. Había fuga de capitales y las inversiones extranjeras no estaban llegando. En 1960, ALm había expropiado la industria eléctrica y ello ahuyentó las inversiones. Otra razón es que el gobierno de ALM se estaba mostrando favorable a Cuba. Este 
asunto le preocupaba al presidente y por ello consultó con sus secretarios de Hacienda, Antonio Ortiz Mena, y de Industria y Comercio, Raúl Salinas Lozano. De acuerdo con Arthur Smith, su respuesta fue que México debía asumir una posición más "pragmática” en Punta del Este para no afectar la economía del país. ${ }^{36}$ Por lo tanto, mostrar una actitud anticomunista representaba un importante win-set para ALM en Punta del Este.

El proceso de toma de decisiones durante la reunión: los grupos de presión y los win-sets

A pesar del voto en contra en el Consejo de la oEA, México tuvo que asistir a la reunión en Punta del Este. Por lo tanto, la SRE realizó todos los preparativos necesarios para que el canciller, Manuel Tello Barraud, pudiera asistir. Antes de llegar a Uruguay, el secretario Tello realizó una visita a Brasil para entrevistarse con San Tiago Dantas, canciller de ese país. De acuerdo con el diplomático mexicano, la reunión sirvió para intercambiar opiniones y "fijar" una postura común. ${ }^{37}$ Esto claramente representaba una estrategia para fortalecer el win-set de México en el nivel I, puesto que Brasil y México buscaban convertirse en los líderes de la soft-line. Una vez iniciada la reunión, el presidente cubano, Osvaldo Dorticós, pidió a Tello una reunión privada. Era claro que Cuba quería establecer estrategias en el nivel i para fortalecer su posición en la sesión de la oEA. El gobierno de la isla veía a México como un líder regional y buscaba influir su posición y su decisión sobre el voto respecto a las posibles sanciones a la isla. El embajador Tello aceptó tener la reunión privada con el funcionario cubano para discutir el tema. ${ }^{38}$

36 Arthur Smith, op. cit., p. 145.

${ }^{37}$ Loc. cit.

38 Ana Covarrubias y Laura Muñoz, Manuel Tello: por sobre todas las cosas México, México, sRe, 2007, p. 38. 
La viII reunión de Consulta de la oea tuvo lugar en el Hotel San Rafael del centro turístico de Punta del Este, Uruguay, del 22 al 31 de enero. Normalmente esas citas se llevaban a cabo en la capital del país, pero los organizadores quisieron evitar inconvenientes por la posibilidad de marchas de protesta en contra de Estados Unidos y a favor de Cuba. La delegación mexicana estuvo integrada por Manuel Tello, secretario de Relaciones Exteriores; Vicente Sánchez Gavito, representante de México ante la oeA; los embajadores Alfonso García Robles, Antonio Gómez Robledo, Manuel Y. de Negri, y los senadores Manuel Moreno y Rodolfo Brena, así como el ministro Ismael Moreno. El secretario general de la delegación era Manuel Tello Macías, hijo del canciller y quien más adelante se convirtió en secretario de Relaciones Exteriores en el sexenio de Carlos Salinas de Gortari.

Para México, los votos en la reunión se convirtieron rápidamente en un asunto estratégico de alta prioridad para la política exterior de México. En casa había mucha polarización y ALM estaba interesado en reducirla. Al iniciar la reunión, era claro que la delegación mexicana tenía un dilema muy difícil de resolver. Por un lado, el win-set del nivel II para el gobierno de ALM era satisfacer las preferencias de los grupos nacionalistas (tablero 3) que demandaban que México apoyara a Cuba, mantuviera sus principios tradicionales y rechazara cualquier injerencia estadounidense en la isla. Al mismo tiempo, el win-set de los grupos de derecha (tablero 4) era asumir una posición anticomunista. ALM sabía que una posición cercana a ellos se convertía en una señal positiva para la economía de México. Por otro lado, el win-set en el nivel I (tablero 2) de ALM era buscar una opción aceptable para Estados Unidos que garantizara la cooperación bilateral y la solución de los problemas mutuos pero, al mismo tiempo, el presidente estaba interesado en mostrar independencia frente al vecino país del norte y mantener una política exterior basada en los principios tradicionales, lo que representaba un win-set en el tablero 1 del 
nivel I. Finalmente, el presidente mexicano buscaba una posición que no molestara a Cuba para no tener represalias y que Castro no financiara grupos revolucionarios en México. Por lo tanto, el asunto era muy complicado e inclusive resultaba contradictorio. Por lo tanto, la decisión requería dotes pragmáticos para resolver la situación e impulsar los win-sets de México. En resumen, el principal interés del gobierno mexicano era declararse anticomunista para mandar una señal positiva a los mercados, pero sin abandonar los principios. Es decir, era necesario recurrir al pragmatismo principista.

Un punto importante es inferir si Tello llegó a Uruguay con una decisión ya tomada o si, dependiendo de las diferentes posiciones, la delegación de México tomaría la decisión ya en la reunión. De acuerdo con Tello, algunos temas ya estaban resueltos y otros se irían construyendo a lo largo de las discusiones. Por ejemplo, en sus memorias, Tello menciona que lo único que estaba decidido previamente era el discurso para la defensa de la incompatibilidad del comunismo en la OEA. El presidente lo leyó y lo aprobó. El secretario de Relaciones Exteriores también menciona en la misma fuente que tenía libertad para emitir los votos necesarios en la reunión. ${ }^{39}$ Para ello, antes de llegar, Tello solicitó ser el segundo orador en la reunión de apertura. Era claro que había un alto interés de asumir una posición de liderazgo desde el principio para más adelante usarla como ficha de negociación ante los diferentes tableros.

En la sesión de apertura del 23 de enero, el secretario Tello emitió un discurso muy fuerte en contra del régimen de Castro. Este discurso se convirtió en una estrategia clave para aumentar el win-set de México en los tableros 2 y 4 durante la reunión. En su oportunidad, el canciller mexicano argumentó que el sistema marxista-leninista era totalmente "incompatible" con las aspiraciones democráticas de los países incluidos en la oEA. En el discurso, Tello aceptó que "las

${ }^{39}$ Manuel Tello, op. cit., p. 119. 
declaraciones hechas por el primer ministro de Cuba, Fidel Castro $[\ldots]$ han introducido un elemento de carácter político en la consideración de este difícil problema", puesto que por primera vez un gobierno latinoamericano adoptaba una ideología "extraña". El canciller también sentenció: "No somos neutrales ni como partes del sistema interamericano ni como miembros de la organización mundial". Sin embargo, Tello anunció que México pediría que se aplicara el principio de no intervención. Esta estrategia aumentaba el win-set en los tableros 1 y 3. En la parte más importante de su discurso, el secretario Tello afirmó:

Parece, pues, indudable que existe una incompatibilidad radical entre la pertenencia a la Organización de los Estados Americanos y una profesión política marxista-leninista como lo sería también una con profesión monárquica absoluta. Con la misma energía con que defendemos el derecho de autodeterminación de los pueblos, del pueblo cubano por consiguiente, sostenemos que es inconciliable la calidad de miembro de nuestra Organización con la adopción de un régimen de gobierno cuyas características no son las de las democracias representativas. $^{40}$

Este párrafo combinaba los win-sets de los cuatro tableros y reflejaba el pragmatismo principista. La noción de la incompatibilidad incluso generó expectativas de que México estaría dispuesto a votar a favor de la expulsión de Cuba del organismo regional. Sin embargo, el discurso era una pieza clave del juego del doble nivel de México. ${ }^{41}$ Por un

${ }^{40}$ Secretaría de Relaciones Exteriores, "Discurso pronunciado por el señor don Manuel Tello, secretarios de Relaciones Exteriores en la Primera Sesión Plenaria de la viı Reunión de Ministros de Relaciones Exteriores de las Repúblicas Americanas, efectuada en Punta del Este, Uruguay, el día 24 de enero de 1962", Serie Problemas Nacionales e Internacionales, México, 1962.

${ }^{41}$ El discurso revestía mucha importancia en la estrategia de México. Incluso, la SRE lo publicó en forma de libro y lo tradujo y distribuyó por 
lado, el objetivo de enfatizar la no compatibilidad era maximizar los win-sets en los tableros 2 y 4 . Por el otro, la insistencia en los principios tradicionales de la política exterior de México era para aumentar el tamaño del win set respecto a los tableros 1 y 3 .

La reunión se extendió varios días debido a lo difícil de las negociaciones. Algunas delegaciones estaban a favor de aplicar severas sanciones a Cuba, mientras que otras se mostraban más moderadas. Estados Unidos abandonó la idea de un rompimiento colectivo a cambio de la exclusión de la isla en la organización. Otro tema fundamental fue la declaración colectiva de que la democracia era el sistema que todos debían adoptar y de que el marxismo-leninismo era totalmente incompatible. Otras cuestiones discutidas fueron las sanciones económicas a Cuba, la reiteración de los principios de no intervención, la Alianza para el Progreso, entre otros.

El proceso de negociación era muy complicado porque había varias propuestas. La idea era aplicar sanciones a Cuba, pero no había claridad de la forma en que se haría. Las principales propuestas eran un rompimiento colectivo de relaciones con Cuba, aplicación del artículo 6 del TIAR que implicaba una posible intervención militar, declarar la incompatibilidad del comunismo en el seno de la OEA, la expulsión de Cuba de la organización, un bloqueo económico. En cuanto a la preferencia de cada país (ver cuadro 3) había prácticamente tres grupos, los que estaban a favor de sancionar a Cuba, los indecisos y los que optaban por la no intervención.

todo el mundo. La idea era mostrar que México era un país anticomunista, pero que se apegaba al derecho internacional. Ver el expediente III5648-1 del Archivo de la SRE. Particularmente el oficio: Circular 122 del 24 de enero de 1962. 


\section{CuAdro 3}

Posiciones al inicio de la reunión

\begin{tabular}{|l|l|l|}
\hline \multicolumn{1}{|c|}{ País } & \multicolumn{1}{c|}{ Posición } & \multicolumn{1}{c|}{ Preferencia } \\
\hline Argentina & $\begin{array}{l}\text { Rompimiento de relaciones con Cuba } \\
\text { sin llegar a sanciones completas }\end{array}$ & No intervención \\
\hline Bolivia & A favor de la no intervención & No intervención \\
\hline Brasil & $\begin{array}{l}\text { Una opción viable, pero evitando la } \\
\text { intervención }\end{array}$ & No intervención \\
\hline Cuba & En contra de la intervención & No intervención \\
\hline Chile & No intervención & No intervención \\
\hline Haití & Ninguna sanción & No intervención \\
\hline Ecuador & No intervención & No intervención \\
\hline México & No intervención & No intervención \\
\hline Centroamérica & Castigo enérgico a Castro & Sancionar a Cuba \\
\hline Colombia & Sanciones severas a Castro & Sancionar a Cuba \\
\hline Estados Unidos & Sanciones a Cuba & Sancionar a Cuba \\
\hline Perú & Fuerte acción en contra de Castro & Sancionar a Cuba \\
\hline República Dominicana & Castigo a Castro & Sancionar a Cuba \\
\hline Paraguay & Sin definición clara al inicio & Indeciso \\
\hline Uruguay & Sin definición clara al inicio & Indeciso \\
\hline Venezuela & Flexibilidad & Indeciso \\
\hline
\end{tabular}

Fuente: El Universal, 22 de enero de 1962, p. 1.

De acuerdo con Tello, la delegación tenía la libertad de emitir un voto en contra de la resolución de la exclusión. Sin embargo, los principales países buscaron negociar una posición común. Fue así como Argentina, Brasil, Colombia, Chile, Bolivia, Haití y México decidieron abstenerse. En ese momento, la oEA estaba compuesta por 21 países. De acuerdo con los estatutos, una decisión de esa naturaleza requería el voto a favor de dos terceras partes de los miembros, es decir, de 14. Haciendo cuentas, Estados Unidos solamente contaba con 13 porque 7 países se abstendrían y uno estaría en contra, Cuba. Estando así las cosas, Washington tuvo que negociar un voto entre los países que se abstendrían. Varias fuentes señalan que 
Estados Unidos compró el voto de Haití. ${ }^{42}$ Es decir, desde la perspectiva de los win-sets de Putnam, Washington adoptó esta estrategia para alcanzar su objetivo. Con el voto de Haití, 14 países apoyaron a Estados Unidos, apenas los suficientes votos para que la viII resolución fuera aprobada. Sin embargo, el triunfo de Washington se consideró cuestionado internamente porque los principales países de la oEA no habían apoyado su propuesta.

\section{Cuadro 4}

Votos de México, viıI Reunión de Consulta de la oEA, 1962

\begin{tabular}{|c|c|c|}
\hline Resolución & Propuesta & Voto de México \\
\hline $\begin{array}{l}\text { I. Ofensiva del comunismo en } \\
\text { América }\end{array}$ & $\begin{array}{l}\text { La unidad continental está en peligro } \\
\text { debido a la amenaza comunista. Hay una } \\
\text { intensificación de la ofensiva subversiva } \\
\text { de gobiernos comunistas. Los principios } \\
\text { del comunismo son incompatibles con el } \\
\text { sistema interamericano y no es el camino } \\
\text { para lograr el desarrollo económico. }\end{array}$ & A favor \\
\hline $\begin{array}{l}\text { II. Comisión Especial de Consulta } \\
\text { sobre Seguridad contra la Acción } \\
\text { Subversiva del Comunismo } \\
\text { Internacional }\end{array}$ & $\begin{array}{l}\text { Solicitar al Consejo de la OEA mantener } \\
\text { vigilancia para prevenir cualquier acto de } \\
\text { agresión. } \\
\text { Encargar al Consejo de la OEA una Comisión } \\
\text { Especial de Consulta. }\end{array}$ & A favor \\
\hline \multicolumn{3}{|l|}{$\begin{array}{l}\text { III. Reiteración de los principios } \\
\text { de no intervención y de } \\
\text { autodeterminación }\end{array}$} \\
\hline Considerandos & & A favor \\
\hline Primer punto resolutivo & $\begin{array}{l}\text { Reiterar la adhesión a los principios de } \\
\text { autodeterminación y no intervención. }\end{array}$ & A favor \\
\hline Segundo punto resolutivo & $\begin{array}{l}\text { Instar a los gobiernos miembros a } \\
\text { constituirse mediante elecciones libres. }\end{array}$ & A favor \\
\hline Resolución en conjunto & & A favor \\
\hline
\end{tabular}

${ }^{42}$ Manuel Tello, op. cit., p. 120 y 136. 
Cuadro 4 (continúa)

Votos de México, viıI Reunión de Consulta de la OEA, 1962

\begin{tabular}{|c|c|c|}
\hline IV. Celebración de elecciones libres & $\begin{array}{l}\text { Recomendar a los gobiernos de los Estados } \\
\text { americanos que procedan a la celebración } \\
\text { de elecciones libres. }\end{array}$ & A favor \\
\hline $\begin{array}{l}\text { V. Alianza para el Progreso del } \\
\text { Sistema Interamericano }\end{array}$ & $\begin{array}{l}\text { Preservación y fortalecimiento de las } \\
\text { instituciones libres y democráticas como } \\
\text { condición para impulsar el desarrollo } \\
\text { económico y social. } \\
\text { Impulsar las industrias básicas y liberalizar el } \\
\text { intercambio de materias primas. } \\
\text { Aprovechar los recursos naturales. }\end{array}$ & A favor \\
\hline \multicolumn{3}{|l|}{ VI. Exclusión de Cuba } \\
\hline Considerandos & & Abstención \\
\hline Primer punto resolutivo & $\begin{array}{l}\text { La adhesión de un miembro de la OEA al } \\
\text { marxismo-leninismo es incompatible con el } \\
\text { sistema interamericano. }\end{array}$ & A favor \\
\hline Segundo punto resolutivo & $\begin{array}{l}\text { El gobierno de Cuba es incompatible con } \\
\text { los principios y propósitos del sistema } \\
\text { interamericano. }\end{array}$ & A favor \\
\hline Tercer punto resolutivo & $\begin{array}{l}\text { La incompatibilidad excluye al actual } \\
\text { gobierno de Cuba de su participación en el } \\
\text { sistema interamericano. }\end{array}$ & Abstención \\
\hline Cuarto punto resolutivo & $\begin{array}{l}\text { El Consejo de la OEA adopte sin demora las } \\
\text { providencias necesarias para cumplir esta } \\
\text { resolución. }\end{array}$ & Abstención \\
\hline $\begin{array}{l}\text { Proyecto de resolución en } \\
\text { conjunto }\end{array}$ & & Abstención \\
\hline $\begin{array}{l}\text { VII. Junta Interamericana } \\
\text { de Defensa }\end{array}$ & $\begin{array}{l}\text { Excluir a Cuba como miembro de la Junta } \\
\text { Interamericana de Defensa. }\end{array}$ & A favor \\
\hline \multicolumn{3}{|l|}{ VIII. Relaciones Económicas } \\
\hline Primer punto resolutivo & $\begin{array}{l}\text { Suspender el comercio y tráfico de armas } \\
\text { con Cuba. }\end{array}$ & Abstención \\
\hline Segundo punto resolutivo & $\begin{array}{l}\text { Encargar al Consejo de la oEA estudiar la } \\
\text { posibilidad de extender la suspensión del } \\
\text { comercio de armas a otros artículos. }\end{array}$ & Abstención \\
\hline
\end{tabular}




\section{Cuadro 4 (conclusión)}

Votos de México, viı Reunión de Consulta de la oEA, 1962

\begin{tabular}{|l|l|l|}
\hline \multicolumn{1}{|c|}{ Tercer punto resolutivo } & $\begin{array}{l}\text { Facultar al Consejo de la oEA para dejar sin } \\
\text { efecto la medida anterior en el momento } \\
\text { que Cuba demuestre su compatibilidad con } \\
\text { los objetivos y principios del sistema. }\end{array}$ & Abstención \\
\hline $\begin{array}{l}\text { Proyecto de resolución en } \\
\text { conjunto }\end{array}$ & Abstención \\
\hline $\begin{array}{l}\text { IX. Reforma del Estatuto de la } \\
\text { Comisión Interamericana de } \\
\text { Derechos Humanos }\end{array}$ & $\begin{array}{l}\text { Recomendar al Consejo de la oEA una } \\
\text { reforma a este estatuto para la promoción } \\
\text { del respeto a los derechos humanos. }\end{array}$ & A favor \\
\hline
\end{tabular}

Fuente: elaboración propia a partir del "Informe sobre la Octava Reunión de Consulta de Ministros de Relaciones Exteriores para Servir de Órgano de Consulta de Acuerdo con lo Establecido en el Tratado Interamericano de Asistencia Recíproca", Archivo SRE, III-5648-1 Informes Sobre la Reunión de Consulta de Ministros de Relaciones Exteriores, que se Verificó en Uruguay 1962.

Como se puede ver en este cuadro, hubo varios temas que se sometieron a votación durante la viII Reunión de Consulta. México votó a favor en la mayoría de las resoluciones. Por ejemplo, aceptó que la adhesión de un miembro de la oEA al marxismo-leninismo era incompatible con el sistema interamericano. De la misma manera, México votó a favor de que el gobierno de Cuba era incompatible con los principios y propósitos del sistema interamericano, lo cual representaba una dura crítica a Castro. También Tello votó a favor de excluir a Cuba de la Junta Interamericana de Defensa. Estos votos representan una clara evidencia de que, en la práctica, México estaba adoptando una posición anticomunista y se estaba alineando a los intereses de Estados Unidos, como lo marca la hipótesis de este artículo. Es decir, la administración de López Mateos se inclinó a maximizar sus win-sets en los tableros 2 (nivel I) y 4 (nivel II). A todas luces, la resolución más importante de la reunión era el tercer punto resolutivo de la sección vi sobre la exclusión de Cuba. En este 
caso, México se abstuvo. Es decir, esta opción representaba ventajas en el marco de los cuatro tableros porque maximizaba los win-sets para los cuatro tableros, como más adelante se discutirá en la sección de análisis.

Por otra parte, y como estrategia para ampliar su win-set respecto a los tableros 1 y 3 , la delegación mexicana pidió la inclusión de una reserva en el acta final de la reunión. Esta establecía que:

La Delegación de México desea dejar constancia en el Acta Final de la Octava Reunión de Consulta de Ministros de Relaciones Exteriores de que, en su concepto, la exclusión de un Estado Miembro no es jurídicamente posible sin la modificación previa de la Carta de la Organización de los Estados Americanos conforme el procedimiento previsto en el Artículo 111 de la misma. ${ }^{43}$

Esta reserva fue incluida para reflejar que el gobierno de México se estaba apegando al marco jurídico de la oeA y representaba una opción congruente con los principios tradicionales de la política exterior de México. El objetivo era, en parte, satisfacer los intereses de los grupos nacionalistas mexicanos (tablero 3) para reducir las manifestaciones de descontento y generar mayor consenso interno, lo cual era clave para que el partido oficialista pudiera mantenerse en el poder. Esta opción estaba también orientada a construir un acercamiento con Castro y evitar represalias. De esta manera, México demostraba cierta autonomía frente a Estados Unidos.

43 “Acta Final de la Octava Reunión de Consulta de Ministros de Relaciones Exteriores para Servir de Órgano de Consulta en Aplicación del Tratado Interamericano de Asistencia Recíproca", https://www.oas.org/ consejo/sp/rc/rcactas.asp 
Análisis de los win-sets de acuerdo con el juego del doble nivel, de Robert Putnam

El argumento aquí es que, de acuerdo con la teoría de Putnam, el voto de abstención sobre la expulsión de Cuba de la OEA era la opción óptima para maximizar el win-set del gobierno mexicano durante la reunión. En otras palabras, esta alternativa representaba mayores ventajas para México porque reflejaba una posición neutral. Un voto a favor satisfacía los intereses de Estados Unidos y de los grupos de derecha internos. Sin embargo, esa opción contradecía las preferencias de Cuba y de los grupos nacionalistas. Un voto en contra reflejaba los intereses del tablero 1 y 3 , pero era incompatible con los tableros 2 y 4 .

Tratando de reflejar estas alternativas de forma numérica, es posible plantear lo siguiente: un voto a favor de la expulsión de Cuba representaba un amplio win set (2 puntos) frente a Estados Unidos y a los grupos de derecha nacionales. Pero representaría uno muy bajo (0 puntos) frente a Cuba y los grupos de izquierda internos. En el mismo sentido, un voto en contra de la expulsión representaría un win-set amplio (2 puntos) frente a Cuba y a los grupos nacionalistas. Sin embargo, sería muy bajo (0 puntos) frente a Estados Unidos y los grupos de derecha. En cambio, un voto de abstención representaba un win set de tamaño medio (1 punto) para todos los tableros debido a las razones que mencionamos a continuación. Por un lado, en el nivel I, Washington sabía que para México las presiones internas eran importantes y no quería ejercer mucha coacción sobre el gobierno priista. Para el gobierno de Estados Unidos, apoyar la estabilidad del sistema político mexicano representaba ventajas para sus intereses económicos. De aquí nace la idea de la política de "agree to disagree" (estar de acuerdo en no estar de acuerdo), la cual plantea que Washington estaría de acuerdo en que México mantenga una posición contraria en temas no prioritarios para Estados Unidos, si eso le ayuda a mantener mayor control interno. 
Además, el discurso de incompatibilidad de Tello y los votos a favor en las resoluciones sobre ese tema habían dejado satisfecho a Washington. Por lo tanto, un voto de abstención era aceptable para Estados Unidos.

Por otro lado, la abstención de México no afectaba de manera significativa a Cuba puesto que el régimen de Castro estaba consciente de que existía el consenso mínimo en la oEA para excluirlo de la organización y sabía de la necesidad de México de no contradecir a Estados Unidos en su lucha contra el comunismo. Además, la reserva en el acta final de la reunión compensaba a Cuba y reflejaba tanto el apego a los principios tradicionales de política exterior como cierta autonomía frente a Washington.

El voto de abstención tampoco tendría efectos negativos en los tableros 3 y 4 (nivel II) porque ninguno interpretaría que el gobierno los estaba traicionando. En el tablero 3, el presidente había neutralizado a Lázaro Cárdenas y la izquierda se había dividido. Por lo tanto, la abstención no generaría grandes protestas por ese lado. El tablero 4 también había quedado satisfecho con el discurso de Tello que defendió la incompatibilidad del comunismo en la oEA.

El cuadro 5 refleja cuantitativamente los argumentos anteriores. En todas las opciones, la suma es igual a 4. Es decir, todas las alternativas tienen las mismas ventajas numéricas. Sin embargo, las dos primeras presentan dos ceros, lo que disminuiría el tamaño del win-set y podría afectar el resultado, porque la decisión estaría completamente en contra de las preferencias de dos tableros. En cambio, la abstención tendría un número positivo en los cuatro tableros. Por lo tanto, la abstención era la opción óptima dado que, de alguna manera, todos los actores tendrían un beneficio y no habría repercusiones negativas significativas. En concreto, el argumento aquí es que el gobierno de México tomó la decisión de abstenerse de expulsar a Cuba porque esa opción ofrecía más ventajas y beneficios. 


\section{CUADRO 5}

Tamaño de los win-sets durante la reunión de la oEA sobre el voto de expulsión a Cuba

\begin{tabular}{|l|c|c|c|c|c|}
\hline $\begin{array}{c}\text { Tipo de voto para } \\
\text { la expulsión }\end{array}$ & $\begin{array}{c}\text { Nivel I, } \\
\text { tablero 1 }\end{array}$ & $\begin{array}{c}\text { Nivel I, } \\
\text { tablero 2 }\end{array}$ & $\begin{array}{c}\text { Nivel II, } \\
\text { tablero 3 }\end{array}$ & $\begin{array}{c}\text { Nivel II, } \\
\text { tablero 4 }\end{array}$ & Total \\
\hline En contra & 2 & 0 & 2 & 0 & 4 \\
\hline A favor & 0 & 2 & 0 & 2 & 4 \\
\hline Abstención & 1 & 1 & 1 & 1 & 4 \\
\hline
\end{tabular}

2 equivale a amplio, 1 a medio y 0 a muy bajo.

Fuente: elaboración propia.

La abstención también reflejaba la política del juego del doble nivel, de Robert Putnam, porque López Mateos buscaba satisfacer a quienes están representados en los cuatro tableros. Esta posición también expresa el pragmatismo principista de la política exterior de México. La administración de López Mateos implícitamente estaba en contra de la exclusión de Cuba de la OEA, pero no lo quiso hacer explícito para no contrariar a los grupos conservadores ni a Washington. En resumen, el gobierno mexicano buscó aparentar que apoyaba a Cuba, pero en la realidad se inclinó hacia Estados Unidos. La férrea defensa de la incompatibilidad del comunismo en la oeA y los distintos votos en la reunión comprueban que México no estuvo a favor de Castro en la reunión. La idea era alinearse a los intereses de Estados Unidos para obtener ventajas, tal como lo plantea la teoría de los win-sets de Putnam.

\section{Los cuatro tableros después de la Reunión}

A final de cuentas, era claro que México se había inclinado a favor de mostrar una posición anticomunista en Punta del Este. En términos prácticos, al país le fue bien después de la reunión. Así, la Bolsa de Valores subió después del discurso 
de incompatibilidad de Tello. ${ }^{44}$ Asimismo, las inversiones extranjeras empezaron a aumentar gracias a la actitud anticomunista de México y a otros factores de naturaleza económica. Los problemas financieros que el país tenía a finales de 1961 empezaron a resolverse a lo largo de 1962 y la economía empezó a crecer de manera sostenida. Los empresarios estuvieron de acuerdo con los resultados de la reunión en Punta del Este y los grupos nacionalistas no protestaron por la abstención. El pragmatismo principista le había servido a ALM.

Por su parte, el gobierno de Castro tampoco tomó represalias contra México. A la Cuba comunista ya no le interesaba estar en un organismo regional con predominio estadounidense. Además, de acuerdo con Mario Ojeda, no hay evidencia de que Castro financiara grupos subversivos en México para derrocar al PRI. ${ }^{45}$ En este aspecto, el voto de abstención y la reserva en el acta final sirvieron para tal propósito.

La opinión pública estadounidense no quedó contenta con el resultado de la reunión debido a que apenas se logró sacar la resolución de la exclusión con los votos suficientes, pero Washington estaba consciente de que los problemas internos en esos países los habían obligado a actuar de esa forma. ${ }^{46}$ Sin embargo, la relación México-Estados Unidos no sufrió descalabros. Al contrario, en junio de 1962 el presidente JFk visitó la Ciudad de México y sostuvo reuniones con ALM. En esta gira, ambos presidentes se pusieron de acuerdo para resolver problemas pendientes. México logró tener acceso a fondos de la Alianza para el Progreso y a préstamos de bancos estadounidenses, y lo más importante fue que, en esa reunión, JFK estuvo de acuerdo en la devolución de El Chamizal, un territorio que 100 años atrás Estados Unidos había

44 "Alza notable en la Bolsa de Valores", El Universal, 26 de enero de 1962, p. 1.

${ }^{45}$ Mario Ojeda, Alcances y límites de la política exterior de México, México, El Colegio de México, 1976.

${ }^{46}$ Foreign Relations of the United States, 1961-1963, Volume XII, American Republics, "Telegram 144 From Secretary of State Rusk to the Department of State, Punta del Este, 31 de enero de 1962. 
tomado de manera ilegal. De igual forma, los dos países sentaron las bases para llegar a un arreglo sobre la salinidad del Río Colorado. ${ }^{47}$ La estrategia de defensa de la incompatibilidad del comunismo había funcionado. El pragmatismo principista dio frutos.

En cuanto al proceso de toma de decisiones, es claro que estuvo centrado en el presidente y en sus más cercanos colaboradores; en este caso el canciller Tello y su equipo, así como los secretarios de Hacienda e Industria y Comercio. López Mateos optó por una posición más pragmática (pero arropada en principios) para poder resolver los problemas económicos que en ese momento eran prioridad. Sin embargo, hay que reconocer que López Mateos consideró las preferencias y presiones de los cuatro tableros para tomar su decisión.

\section{LA REUNIÓN DURANTE LA CRISIS DE LOS MISILES: EL APOYO DE MÉXICO}

En octubre de 1962, los servicios de inteligencia de Estados Unidos descubrieron que la Unión Soviética había instalado bases de lanzamiento de misiles nucleares en Cuba. Como nunca, la medida representaba una grave amenaza a la seguridad nacional de Estados Unidos y ponía al mundo al borde de una guerra nuclear. Por lo tanto, la política exterior de Estados Unidos se enfocó en el retiro de los misiles de la isla. Kennedy utilizó varias estrategias tanto bilaterales como multilaterales. La más importante fue establecer un bloqueo naval sobre Cuba para evitar que buques soviéticos llevaran a la isla más equipo militar. Para ello, Kennedy necesitaba una base jurídica muy sólida para justificar el bloqueo. En la ONU no podía obtenerla porque la uRss automáticamente la veta-

${ }^{47}$ Foreign Relations of the United States, 1961-1963, Volume XII, American Republics 147. "Memorandum of Conversation", Ciudad de México, 29 de junio de 1962, 4:45 p.m. 
ría. Por lo tanto, su carta fuerte era la oEA. Es decir, Kennedy necesitaba una resolución que respaldara su política para exigir a la URss el retiro de los misiles. El objetivo era mostrar que los misiles representaban una amenaza para toda la región latinoamericana y que la decisión de Estados Unidos no era unilateral. Una resolución aprobada por todos los miembros de la oEA se convirtió en una estrategia vital para Kennedy y una posible carta de negociación frente a Nikita Khrushchev. ${ }^{48}$

Un problema importante era saber si Washington podía contar con los votos suficientes de los países latinoamericanos para operar su estrategia. Unos meses atrás, su propuesta había tenido solamente el apoyo de 14 países de 21. A Kennedy le interesaba, de ser posible, tener un voto unánime. Para ampliar su win-set y garantizar el logro de ese objetivo, el Departamento Estado envió instrucciones a los embajadores estadounidenses en los países latinoamericanos de entregar, personalmente, una carta dirigida a los presidentes en la que JFK pedía de manera directa su apoyo. El Departamento de Estado informó a los embajadores que era de vital importancia la aprobación de una resolución para exigir el retiro de los misiles y tomar todas las acciones necesarias según lo previsto en el artículo 8 del Pacto de Río. ${ }^{49}$

La estrategia de Kennedy involucraba a México de manera directa. Sin embargo, el principal problema era que el presidente y el secretario de Relaciones Exteriores estaban en esos momentos en Filipinas en una gira por el continente

48 Sobre la importancia para Kennedy de la resolución en la OEA, véase Renata Keller, "'Responsibility of the Great Ones': How the Organization of American States and the United Nations Helped Resolve the Cuban Missile Crisis", Journal of Latin American Studies, (2019), 1-22. Consultar también Robert Kennedy, Thirteen Days: A Memoir of the Cuban Missile Crisis, Nueva York, Norton and Company, 1969.

${ }^{49}$ Foreign Relations of the United States, 1961-1963, Volume XII, American Republics, Circular telegram 700 to all Latin American posts, October 21. Instructions for Ambassadors following the President's nationwide TV statement on Soviet offensive nuclear capability in Cuba. Top Secret. 5 pp. DOS, CF, 737.00/10-2262. 
asiático. El canciller mexicano relata que la noche del 22 de octubre (hora de Filipinas) recibió al embajador de Estados Unidos en Filipinas, quien llevaba una carta de JFK dirigida a ALM, e insistía en entregarla de manera inmediata y en persona, debido a que era un asunto de "extrema urgencia". Ya era muy tarde y no pudieron entrar en contacto con el presidente ALM; acordaron verse muy temprano al otro día. Manuel Tello informó al presidente a primera hora y recibieron al embajador estadounidense, quien leyó la carta de JFK. De acuerdo con el canciller, ambos quedaron "anonadados" porque la posibilidad de una conflagración nuclear era inminente..$^{50}$

Después de la reunión, el presidente ALM ofreció una conferencia de prensa. Ahí le preguntaron de manera directa su posición respecto a Cuba. Para esa hora, ya se conocía el discurso de Kennedy, en donde informaba a su nación y al mundo la existencia de los misiles en la isla. López Mateos afirmó que México defendería la paz mundial, así como los principios de no intervención y autodeterminación. Argumentó que Cuba tenía el derecho a tener "armas defensivas", pero que si se convertían en "ofensivas" entonces México aplicaría lo establecido por las normas y las organizaciones regionales, ${ }^{51}$ en este caso la oEA.

El lunes 22 de octubre la Casa Blanca convocó a una reunión extraordinaria del Consejo de la oEA para celebrarse el 23 por la mañana. No había suficiente tiempo para convocar a una reunión de consulta de ministros de Relaciones Exteriores y la emergencia exigía rapidez en las decisiones. El objetivo de Estados Unidos era que la oEA aprobara una resolución que sirviera de base al bloqueo y demandara a la Unión Soviética el retiro inmediato de los misiles que se encontraban en la isla. El presidente Kennedy le exigió a su

50 Manuel Tello, México, una posición internacional, México, Joaquín Mortiz, 1972, pp. 154-157.

51 Gobierno de México, Presencia internacional de Adolfo López Mateos, México, 1963, pp. 391-392. 
secretario de Estado, Dean Rusk, el voto unánime de todos los miembros de la oEA a favor de la medida.

De acuerdo con las memorias de Manuel Tello Macías, hijo del entonces secretario Manuel Tello Barraud, ${ }^{52}$ el representante de México ante la oEA, Vicente Sánchez Gavito, estaba en México en una comisión ${ }^{53}$ y el segundo de a bordo estaba de vacaciones. Manuel Tello Macías era entonces responsable de la misión de México en la oEA. El joven diplomático cuenta que recibió la convocatoria a la reunión del Consejo de la oEA y prácticamente no sabía qué hacer. ${ }^{54}$ De inmediato solicitó instrucciones a la SRE. Tello hijo recibió un telegrama "cifrado" en donde se le instruía a votar "abstención” frente a cualquier resolución que presentara Washington. Horas después recibió una llamada de Antonio Carrillo Flores, en ese entonces embajador de México en Estados Unidos, quien le pidió a Tello que fuera a su oficina lo antes posible. En la reunión, el embajador le dijo que había recibido una llamada del Departamento de Estado para acudir a una cita "urgente" con ellos. Tello informó al embajador que había recibido un telegrama cifrado con la instrucción de votar con abstención y el embajador le contestó que por esa razón lo habían citado. Ahí, Tello comprendió que Estados Unidos espiaba a la misión de México en la oeA y que habían "descifrado" previamente el telegrama. En la cita en el Departamento de Estado, los funcionarios estadounidenses informaron que estaban tratando de localizar al presidente de México para explicarle sobre la urgencia de Estados Unidos para que México votara a favor de la propuesta de Washington.

52 Ana Covarrubias y Laura Muñoz, Manuel Tello: Por sobre todas las cosas México, México, Secretaría de Relaciones Exteriores, 2007.

${ }^{53}$ De hecho, todos los representantes ante la oEA se encontraban en una reunión de la Alianza para el Progreso en la Ciudad de México. Al conocer la convocatoria, todos se dirigieron de inmediato al aeropuerto a tomar un avión para regresar a Washington.

${ }^{54}$ En ese preciso momento el presidente López Mateos y el secretario de Relaciones Exteriores, Manuel Tello Barraud, se encontraban en Filipinas y era de noche, por lo que resultaba difícil contactarlos. 
El 23 por la mañana, tuvo lugar la reunión del Consejo de la OEA. Las discusiones eran fuertes y, en concreto, había dos propuestas. La primera era convertir al Consejo de la OEA en el órgano de consulta, como si se tratara de una reunión de ministros. Sobre este primer punto hubo amplio consenso entre los representantes. La segunda era una resolución que a la letra decía:

1. Instar a que se desmantelen inmediatamente y se retiren de Cuba todos los proyectiles y cualesquiera otras armas con capacidad ofensiva.

2. Recomendar a los Estados Miembros, de conformidad con los artículos 6 y 8 del Tratado Interamericano de Asistencia Recíproca, que adopten todas las medidas individuales y colectivas, incluso el empleo de la fuerza armada, que consideren necesarias para asegurar que el Gobierno de Cuba no pueda continuar recibiendo de las potencias chino-soviéticas, pertrechos y suministros militares que amenacen la paz y la seguridad del Continente, y para impedir que los proyectiles en Cuba con capacidad ofensiva se conviertan en cualquier momento en una amenaza activa contra la paz y la seguridad del Continente.

3. Informar al Consejo de Seguridad de las Naciones Unidas sobre esta Resolución, de conformidad con el Artículo 54 de la Carta de las Naciones Unidas.

4. Continuar actuando provisionalmente como Órgano de Consulta e instar a los Estados Miembros a que se mantenga debidamente informado al Órgano de Consulta sobre las medidas que adopten de acuerdo con el párrafo segundo de la presente Resolución. ${ }^{55}$

El contenido de la resolución era de amplio alcance porque aparecían las palabras "uso de la fuerza" y varios países estaban en contra de este tipo de medidas. Por lo tanto, los repre-

55 Resolution of the Council of the Organization of the American States, October 23, 1962, OAS Doc. OEA/SER.G/III, C-sa-463. 
sentantes pidieron que la votación se dividiera párrafo por párrafo. Por lo tanto, se presentaron 5 votaciones. En el primer párrafo (desmantelamiento de los misiles), México votó a favor. En los párrafos donde aparecía la frase "empleo de la fuerza" y "capacidad ofensiva", el país se abstuvo. En el siguiente párrafo (informar a la onu y actuar como órgano de consulta), México votó a favor. En la resolución en su conjunto, la delegación mexicana votó a favor. Por las implicaciones de la resolución, el representante mexicano pidió la palabra y afirmó que "como la Constitución de México fija límites precisos a las facultades del Poder Ejecutivo, la representación mexicana hace constar expresamente que la eficacia de su voto favorable está determinada por esos límites". Además, al final del acta, la representación mexicana solicitó la inclusión de una reserva que especificaba lo siguiente: "La aprobación de la resolución en su conjunto no debe interpretarse como apoyo a un ataque armado contra Cuba". ${ }^{56}$

\section{CuAdro 6}

Votos de México Consejo de la oea 23 de octubre de 1962

\begin{tabular}{|l|l|}
\hline \multicolumn{1}{|c|}{ Propuesta } & Voto de México \\
\hline $\begin{array}{l}\text { Instar a que se desmantelen inmediatamente y se retiren de Cuba todos } \\
\text { los proyectiles y cualesquiera otras armas con capacidad ofensiva. }\end{array}$ & A favor \\
\hline $\begin{array}{l}\text { Recomendar a los Estados Miembros, de conformidad con los artículos } \\
6 \text { y } 8 \text { del Tratado Interamericano de Asistencia Recíproca, que } \\
\text { adopten todas las medidas individuales y colectivas, incluso el empleo } \\
\text { de la fuerza armada, que consideren necesarias para asegurar que el } \\
\text { Gobierno de Cuba no pueda continuar recibiendo de las potencias } \\
\text { chino-soviéticas, pertrechos y suministros militares que amenacen la paz } \\
\text { y la seguridad del Continente }\end{array}$ & \\
\hline $\begin{array}{l}\text { y para impedir que los proyectiles en Cuba con capacidad ofensiva se } \\
\text { conviertan en cualquier momento en una amenaza activa contra la paz y } \\
\text { la seguridad del Continente. }\end{array}$ & Abstención \\
\hline
\end{tabular}

56 "Acta de la sesión extraordinaria celebrada el 23 de octubre de 1962”, Consejo de la oEA. 
CuAdro 6 (conclusión)

Votos de México Consejo de la oeA 23 de octubre de 1962

\begin{tabular}{|c|c|}
\hline Propuesta & Voto de México \\
\hline $\begin{array}{l}\text { 3. Informar al Consejo de Seguridad de las Naciones Unidas sobre } \\
\text { esta Resolución, de conformidad con el Artículo } 54 \text { de la Carta de las } \\
\text { Naciones Unidas. } \\
\text { 4. Continuar actuando provisionalmente como Órgano de Consulta } \\
\text { e instar a los Estados Miembros a que se mantenga debidamente } \\
\text { informado al Órgano de Consulta sobre las medidas que adopten de } \\
\text { acuerdo con el párrafo segundo de la presente Resolución. }\end{array}$ & A favor \\
\hline Resolución en conjunto & A favor \\
\hline
\end{tabular}

Fuente: elaboración propia a partir del "Acta de la sesión extraordinaria celebrada el 23 de octubre de 1962”, Consejo de la OEA.

Después de la reunión, algunos Estados de la región "ofrecieron unidades navales, aeropuertos, bases navales, facilidades portuarias y otras instalaciones". ${ }^{57}$ En caso de un conflicto, Estados Unidos podía contar con puntos estratégicos desde el punto de vista geopolítico. Diez países ofrecieron bases navales para la aplicación de la cuarentena o en caso de una guerra. La resolución del Consejo de la oEA fue la muestra más amplia de unidad americana después de la SGM. La repentina realidad de que misiles pudieran alcanzar a sus propios países permitió a los presidentes desafiar la opinión pública interna que los había "intimidado" antes. ${ }^{58}$ Cuba quedó aislada. Es probable que la rapidez de la resolución y la unidad latinoamericana haya impactado en la uRss. Por ello, para Kennedy, la unanimidad en la oEA era de vital importancia para su estrategia frente a la URss. Estando así las cosas, México no tenía mucho espacio de maniobra.

57 Stanimir Alexandrov, Self-Defense Against the Use of Force in International Law, La Haya, Kluwer Law International, 1996, p. 243.

58 R. St. J. MacDonald, "The Organization of American States in Action”, The University of Toronto Law Journal, vol. 15, núm. 2, 1964, p. 404. 
Análisis de los win-sets de acuerdo con el Juego del doble nivel, de Robert Putnam

Como observó, la instrucción original que recibió la delegación mexicana ante la oEA de abstenerse se había cancelado desde los niveles más altos del gobierno mexicano. Nueve meses antes, México votó con abstención en un tema que también incluía a Cuba. Es decir, la idea era darle continuidad a esa posición. Sin embargo, la razón que explica el voto diferente fue que en ese momento había una coyuntura especial y urgente para Estados Unidos, que amenazaba su seguridad nacional de manera directa. Es decir, el peso del win-set frente a Washington era muy amplio. En este contexto, la presión estadounidense (tablero 2) fue el factor que explica la decisión de México. Como Kennedy exigía un voto unánime, el Departamento estableció una estrategia clave para logarlo: la carta de petición de apoyo que presentó de manera directa ante los presidentes latinoamericanos.

Los tableros 1 y 3 eran importantes para el proceso de toma de decisiones, pero no determinantes. La administración de ALM jugó prácticamente con un solo tablero. El voto a favor de la resolución satisfacía ampliamente los intereses de Estados Unidos y mostraba la actitud anticomunista de México. Los votos de abstención en los párrafos controversiales, la reserva y la anotación de la Constitución estaban dirigidos a los grupos nacionalistas porque, aun así, se buscaba mostrar cierto grado de independencia frente a Estados Unidos y defender los principios de la política exterior de México. Al día siguiente de la reunión, Manuel Tello explicó las razones de la reserva. Dijo que el país no podía "comprometerse a participar en ninguna acción bélica” porque eran facultades exclusivas del Congreso de la Unión. ${ }^{59}$ En otras palabras, México buscó ampliar su margen de negociación argumentando que ciertas medidas no serían aceptables por

59 "Habla Tello sobre el voto de México", El Universal, 24 de octubre de 1962, p. 1. 
el aparato legislativo, tal como lo plantea la teoría de los winsets de Putnam. Ello le permitió sin problema la abstención en ciertos puntos y la inclusión de la reserva. De nueva cuenta, el pragmatismo principista prevaleció.

De acuerdo con las fuentes consultadas, el proceso de toma de decisiones se concentró en el presidente de la República. El problema fue que, en los momentos más importantes, no se le había podido localizar. Por ello, el gobierno de Estados Unidos recurrió a tres estrategias para convencer al gobierno de México de votar a favor de la resolución. En la primera, el embajador Thomas Mann recurrió al secretario de Gobernación, Gustavo Díaz Ordaz, quien le dijo que México estaría del lado de Estados Unidos. ${ }^{60}$ En una segunda alternativa, el secretario del Tesoro de Estados Unidos, Douglas Dillon, buscó a Antonio Ortiz Mena para revelarle el plan de Estados Unidos y buscar el apoyo del gobierno de ALM. Su respuesta fue: "México entendía que esto no era una simple disputa con Castro, sino un serio desafío con Rusia y que México estaría del lado de Estados Unidos" ${ }^{61}$ La tercera opción se presentó a través del embajador de México en Washington, cuando fue citado al Departamento de Estado para mostrarle la evidencia de que Cuba tenía armas ofensivas. No hay duda de que Adolfo López Mateos ratificó las decisiones de sus funcionarios una vez que fue localizado. En una escala en Hawái, JFK y ALM hablaron por teléfono y el asunto se resolvió. Para Kennedy, el voto de México era particularmente importante en su estrategia frente a los soviéticos. Por eso la urgencia de contactar directamente al presidente de México.

${ }^{60}$ Luis Farías, Así lo recuerdo: testimonio político, México, FCE, 1992. Citado por Esteban Rodríguez, "Durante la 'Guerra Fría', el país fue terreno para la lucha de espías”, El Universal, 28 de septiembre de 2001, https://archivo.eluniversal.com.mx/nacion/67021.html. Véase tambiénRenata Keller, Mexico's Cold War. Cuba, the United States, and the Legacy of the Mexican Revolution, Cambridge, University Press, 2015, p. 138.

61 Citado por Mario Ojeda, México y Cuba revolucionaria. Cincuenta años de relación, México, El Colegio de México, 2008, p. 60. 
Haciendo un análisis cuantitativo similar al caso anterior, en el voto mexicano a favor del desmantelamiento de los misiles en la isla hay diferencias significativas. Un voto en contra obviamente representaba un win-set amplio frente a Cuba (2 puntos), pero muy bajo ante Estados Unidos (0 puntos). Para los grupos nacionalistas, la opción también tenía ventajas, porque el gobierno mostraría independencia ante Estados Unidos y defensa de los principios (2 puntos). Sin embargo, para el tablero 4 esa decisión significaría apoyo al comunismo y el win-set sería demasiado bajo (0 puntos). La abstención representaba en todos los casos un win-set mediano (1 punto) porque era una posición neutral. En cambio, un voto a favor tenía ventajas en los cuatro tableros. Para Estados Unidos, ésa era precisamente la preferencia (2 puntos). En la casilla de Cuba no habría problemas porque López Mateos quedó completamente convencido de apoyar a Estados Unidos debido a que había evidencia de que los misiles en Cuba eran de naturaleza ofensiva. El presidente mexicano se sintió engañado porque el embajador cubano le había informado anteriormente que las armas eran de carácter defensivo. ${ }^{62}$ Por lo tanto, el tamaño del win-set era mediano (1 punto). En el tablero 3, también es posible asignar una dimensión mediana (1 punto) debido a que los diferentes grupos oficiales se alineaban a la figura del presidente; había una fuerte disciplina partidaria en el Congreso (aunque no se requería la ratificación formal) y la izquierda interna estaba todavía dividida. Para el tablero 4, el voto a favor representaba un win-set amplio (2 puntos) porque estaría demostrando una posición anticomunista. En la suma total, el voto a favor representaba 6 puntos, mientras que las otras opciones solamente 4 (véase cuadro 7).

${ }^{62}$ Véase Manuel Tello, op. cit., p. 159. 


\section{Cuadro 7}

Tamaño de los win-sets durante la reunión de la oEA para el desmantelamiento inmediato de los misiles en Cuba

\begin{tabular}{|l|c|c|c|c|c|}
\hline $\begin{array}{c}\text { Tipo de voto para } \\
\text { la expulsión }\end{array}$ & $\begin{array}{c}\text { Nivel I, } \\
\text { tablero 1 }\end{array}$ & $\begin{array}{c}\text { Nivel I, } \\
\text { tablero 2 }\end{array}$ & $\begin{array}{c}\text { Nivel II, } \\
\text { tablero 3 }\end{array}$ & $\begin{array}{c}\text { Nivel II, } \\
\text { tablero 4 }\end{array}$ & Total \\
\hline En contra & 2 & 0 & 2 & 0 & 4 \\
\hline A favor & 1 & 2 & 1 & 2 & 6 \\
\hline Abstención & 1 & 1 & 1 & 1 & 4 \\
\hline
\end{tabular}

2 equivale a amplio, 1 a medio y 0 a muy bajo

Fuente: elaboración propia.

El apoyo de México a Estados Unidos demostró dos cosas. La primera fue que, cuando se trata de un asunto de menor importancia para los intereses nacionales de la Casa Blanca, el gobierno de Estados Unidos le da a México un margen de maniobra amplio incluso para votar en contra de ellos, como fue el caso de Punta del Este. ${ }^{63}$ Sin embargo, en un tema de alta prioridad para la seguridad nacional estadounidense, Washington no ofrece libertad y presiona para que México asuma una posición favorable a sus intereses. Ello explica el voto de México (a favor) en la reunión del Consejo de la OEA. La segunda es que Estados Unidos estaba dispuesto a que el gobierno mexicano mantuviera una política independiente si ello era de ayuda para la estabilidad política del PRI. A Washington le convenía para favorecer sus intereses económicos en su país vecino del sur. La situación en enero era muy distinta a la de octubre. No tenía la misma prioridad expulsar a Cuba de una organización que el retiro de los misiles, lo cual amenazaba de manera directa la propia existencia de Estados Unidos.

${ }^{63}$ Jorge A. Schiavon, "La relación especial México-Estados Unidos: cambios y continuidades en la guerra y posguerra fría", en Jorge A. Schiavon, Daniela Spenser y Mario Vázquez Olivera (eds.), En busca de una nación soberana: relaciones internacionales de México, siglos XIX y XX, México, CIDE-SRE, 2006. 
Es sumamente probable que López Mateos calculara que no habría una reacción negativa entre la opinión pública nacional si México votaba a favor de Estados Unidos, porque representaba una opción que fomentaba el desarme y la seguridad internacional y, en efecto, no hubo reacciones contrarias en los periódicos en esas semanas. ${ }^{64}$ Además, ese voto apaciguaba la crítica que su administración tenía de empresarios y grupos conservadores por mostrarse pro Cuba en ocasiones anteriores. Tampoco México corría un gran riesgo frente a Cuba y la Unión Soviética, porque era comprensible que el país se manifestara a favor del pacifismo y el desarme. Uno de los efectos de la crisis de los misiles fue que, a partir de entonces, México adoptó un férreo compromiso a favor del desarme y la no proliferación de armas nucleares en América Latina y a favor de la paz mundial. Meses más tarde, el propio López Mateos impulsó la negociación de un tratado que prohibiera el uso de la energía atómica para la elaboración de armas en la región, esfuerzo que se concretó en 1967 con el famoso Tratado de Tlatelolco firmado en la Ciudad de México.

La reserva incluida en el acta final enviaba varias señales. En primer lugar, era un guiño a los grupos nacionalistas internos que estaban a favor de Cuba. De igual modo, era un signo positivo hacia Cuba, al defender la no intervención militar en la isla. En segundo lugar, la reserva buscaba mostrar que, a pesar de votar a favor de Estados Unidos, México quería demostrar cierta independencia frente a Washington. Por último, la inclusión de ese instrumento legal mostraba la defensa de México de sus principios tradicionales de política exterior. En resumen, la posición de México en la reunión mantenía la combinación de pragmatismo y principismo.

${ }^{64}$ En la revisión de los periódicos en fechas posteriores al voto, no se encontraron notas negativas para AMLO sobre el apoyo a Estados Unidos. 


\section{El voto de México en la IX Reunión de Consulta de Ministros de Relaciones Exteriores de la OEA: EN BUSCA DE INDEPENDENCIA FRENTE A ESTADOS UNIDOS}

Luego de su triunfo en 1959, Fidel Castro se propuso exportar la Revolución cubana a otras regiones. Su gobierno incluso apoyó movimientos en países africanos, pero el principal objetivo eran algunos países de América Latina. Por ejemplo, Ernesto Che Guevara buscó iniciar un movimiento revolucionario en Bolivia, pero fracasó. Estando así las cosas, varios países de la región temieron que Castro financiara y apoyara grupos revolucionarios. En este contexto, una de las respuestas de Washington fue la Alianza para el Progreso, instrumento cuyo objetivo era el de apoyar financieramente a los países de la región para evitar la llegada de grupos comunistas a los gobiernos que apoyaban los intereses estadounidenses. Otra estrategia fue utilizar de nuevo a la oeA para aislar a Cuba y evitar financiar esos grupos guerrilleros.

En 1964, Venezuela solicitó al Consejo de la oEA la organización de la Ix Reunión de Consulta de Ministros de Relaciones Exteriores. El argumento era que el régimen de Castro estaba apoyando una revolución comunista en ese país y que era necesario aplicar mayores sanciones a la isla. El propósito principal era el rompimiento de relaciones diplomáticas de todos los miembros del organismo con Cuba. A diferencia de la viı Reunión, México votó con abstención a la convocatoria de la Ix Reunión por considerarla contraria a los estatutos de la oEA. De nuevo, el país adoptaba como estrategia de política exterior el apego a las disposiciones legales.

\section{Los cuatro tableros antes de la reunión}

Para la Ix Reunión, México adoptó una nueva estrategia de política exterior. Una vez que se confirmó la reunión a celebrarse en la ciudad de Washington en julio de 1964, el gobierno de López Mateos anunció con amplia anticipación su voto. 
En un boletín de prensa, el nuevo secretario de Relaciones Exteriores, José Gorostiza, anunció que México votaría en contra. ${ }^{65}$ La estrategia buscaba evitar que, ya en la reunión, ningún país pudiera presionar a la delegación mexicana. Asimismo, la idea era impedir el debate entre los grupos nacionalistas y los conservadores. En otras palabras, la administración de López Mateos buscó evitar el juego de los cuatro niveles previo a la reunión. Más tarde, el canciller anunció que no asistiría por tener compromisos de urgencia. De esta manera, al asistir un representante de menor jerarquía, ya no existía la posibilidad de que México pudiera cambiar el sentido de su voto.

El voto en contra del rompimiento de relaciones diplomáticas con Cuba podría apaciguar a los grupos nacionalistas y de oposición al gobierno de López Mateos porque en julio de ese año el PRI había arrasado en las elecciones presidenciales. Los grupos de izquierda habían tenido una enorme derrota y el voto negativo podría ayudar a levantar sus ánimos. El presidente entregaba el poder en diciembre de ese año y quería dejar un país políticamente estable. Por lo tanto, la posición hacia Cuba se orientaba, principalmente, al consumo interno. Aunque hubo manifestaciones de la derecha en México, en ese momento el gobierno de ALM estaba más interesado en reducir la inconformidad de los grupos de izquierda. En este contexto, la cercanía de las elecciones y el final del sexenio explican, en parte, las razones por las cuales ahora México votaba en contra de la posición de Estados Unidos, a diferencia de las dos ocasiones anteriores.

El anuncio anticipado del voto en contra no tuvo impactos negativos con Estados Unidos. Para ese momento, Washington estaba concentrado en otros temas internos y externos. En esos días, el país vivía momentos complicados debido al racismo que imperaba en la sociedad; Lyndon Johnson esta-

${ }^{65}$ Secretaría de Relaciones Exteriores, Dirección General de Prensa y Publicidad, Boletín de Prensa núm. 93, 15 de julio de 1964. Expediente, III-5660-11. 
ba más preocupado por aprobar la Ley de los Derechos Civiles, que en el asunto de Cuba. Además, en política exterior el foco de la Guerra Fría se había trasladado a Vietnam. El incidente del Tonkin ocurrió unos días después de la Ix Reunión en Washington. Por lo tanto, la prioridad ya era el sureste asiático y no Cuba.

\section{La posición legalista de México en la IX Reunión}

La Ix Reunión de Consulta de Ministros de Relaciones Exteriores tuvo lugar en la ciudad de Washington D.C., del 21 al 26 de julio de 1964. La delegación mexicana estuvo encabezada por Vicente Sánchez Gavito, representante de México ante la oEA. Previo a la reunión, la SRE preparó algunos apuntes para la intervención de los representantes mexicanos. ${ }^{66}$ Prácticamente, las instrucciones eran votar en contra de las principales propuestas. México no estaría a favor de la suspensión de comunicaciones aéreas con Cuba. De hecho, fue el único país que mantuvo un vuelo comercial con La Habana después de la reunión. Asimismo, la delegación mexicana se opondría a que la oEA aprobara una resolución para solicitar a otros países no miembros interrumpir el comercio con Cuba.

En la reunión se formaron tres grupos. Venezuela, Colombia y Estados Unidos ( hard-line) estaban a favor de aplicar sanciones estrictas. Por otro lado, México, Uruguay, Bolivia y Chile se oponían a ello (soft-line). Finalmente, Argentina, Brasil y Perú buscaban mediar las posiciones entre ambos bandos. ${ }^{67}$ Sin embargo, al final se impuso la línea dura. La parte central de la reunión era la Resolución I titulada: “Aplicación

66 “oEA. Apuntes para la intervención del Representante de México en el debate general de la Novena Reunión de Consulta de Ministros de Relaciones Exteriores para servir de Órgano de Consulta en aplicación del TIAR", XII/441.2(X)/1.

67 "Se han formado tres grupos en el seno de la OEA", El Universal, 21 de julio de 1964, p. 9. 
de Medidas al Actual Gobierno de Cuba”. El documento condenaba enérgicamente al gobierno de Cuba por sus actos de agresión e intromisión en los asuntos internos de Venezuela. Además, tomaba las siguientes medidas:

[...] que los gobiernos de los Estados americanos no mantengan relaciones diplomáticas ni consulares con el gobierno de Cuba; que los gobiernos de los Estados Americanos interrumpan todo su intercambio comercial directo o indirecto, con Cuba, con excepción de los alimentos, medicinas y equipo médico que por razones humanitarias puedan ser enviados a Cuba, y que los gobiernos de los Estados americanos interrumpan todo transporte marítimo entre sus países y Cuba, con excepción del transporte necesario por razones de índole humanitaria. ${ }^{68}$

Además, la resolución planteaba la posibilidad de usar la fuerza armada en caso de que Cuba persista en realizar actos de agresión. Finalmente, el documento abría la posibilidad para que países no miembros de la oEA se solidarizaran con los propósitos de la resolución. Como lo había anunciado previamente, México votó en contra de cada una de estas medidas; Chile, Uruguay y Bolivia también votaron en contra; Argentina se abstuvo. ${ }^{69}$ Con 15 votos a favor, la resolución se convertía en acatamiento obligatorio para todos los miembros. ${ }^{70} \mathrm{Al}$ final del Acta, como ya era una costumbre, México solicitó la inclusión de las siguientes reservas:

1. Las disposiciones del tercer párrafo resolutivo de la Resolución I (en contra de la cual ha votado la Delega-

68 Acta Final Novena Reunión de Consulta de Ministros de Relaciones Exteriores para servir de órgano de consulta en aplicación del Tratado Interamericano de Asistencia Recíproca, Washington D.C., 21 a 26 de julio de 1964, http:/ / www.oas.org/consejo/sp/RC/RCactas.asp

69 "Acordaron aplicar sanciones a Cuba, por 15 votos contra 4", El Universal, 26 de julio de 1964, p. 1.

70 "Las sanciones son de obligatorio cumplimiento", El Universal, 26 de julio de 1964, p. 4. 
ción de México) carecen de fundamento, en virtud que el Tratado Interamericano de Asistencia Recíproca no contempla en parte alguna la aplicación de las medidas ahí previstas, a situaciones de la naturaleza y características de las que ha examinado esta Reunión de Consulta.

2. Formula reserva sobre lo estipulado en el quinto párrafo resolutivo de la misma resolución, ya que éste pretende ampliar, en forma incompatible con las disposiciones de los artículos 3 y 10 del Tratado Interamericano de Asistencia Recíproca, el derecho de legítima defensa individual o colectiva.

3. Reitera sin reservas "su voluntad de permanente cooperación para realizar los principios y propósitos de una política de paz" a la que "se halla esencialmente ligada" la "obligación de mutua ayuda y de defensa común de las repúblicas americanas", de acuerdo con lo estipulado en el quinto párrafo del TIAR. ${ }^{71}$

Análisis de los win-sets de acuerdo con el juego del doble nivel, de Robert Putnam

En el análisis cuantitativo, el voto en contra del rompimiento de relaciones diplomáticas con Cuba significaba un amplio win-set para México. Claramente, para Cuba (tablero 1) representaba ventajas ( 2 puntos) porque no estaría aislada por completo. Además, el gobierno priista estaba muy interesado en evitar que Castro pudiera financiar grupos guerrilleros en México. El voto en contra era como una vacuna para ese fin. Por otro lado, para Estados Unidos (tablero 2), esa opción representaría un win-set mediano (1 punto) debido a que el

71 Acta Final Novena Reunión de Consulta de Ministros de Relaciones Exteriores para servir de órgano de consulta en aplicación del Tratado Interamericano de Asistencia Recíproca, Washington D.c., 21 a 26 de julio de 1964, http:/ / www.oas.org/consejo/sp/RC/RCactas.asp 
voto en contra también reflejaba el "acuerdo para estar en desacuerdo". Es decir, Washington le daba al PRI margen de maniobra a cambio de garantizar estabilidad política y económica en el país. Incluso le convenía que México mantuviera relaciones diplomáticas con Cuba porque así el gobierno mexicano se convertiría en el único canal de comunicación entre Washington y La Habana. De hecho, Dean Rusk confiesa que, durante la Ix Reunión, algunos miembros conversaron sobre la conveniencia de tener una embajada abierta. ${ }^{72}$ De acuerdo con LeoGrande y Kornbluh, antes de iniciar la reunión, Estados Unidos, Brasil y México acordaron un "pacto secreto" para que el último mantuviera relaciones con Cuba. ${ }^{73}$ Para el tablero 3, el voto en contra del rompimiento representaba un amplio win-set (2 puntos) debido a que esa opción iba acorde con las preferencias de los grupos nacionalistas y de la opinión pública. Finalmente, en el tablero 4, la decisión reflejaba un win-set demasiado bajo (0 puntos) porque mostraba un apoyo al régimen comunista de Castro y los grupos de derecha estaban en contra de esa posición. Sumando el resultado, el voto en contra representaba 5 puntos mientras que las otras opciones solamente 4 (ver cuadro 7).

72 Lyndon B. Johnson Library, National Security Files CO-Mexico, "Díaz Ordaz visit, 1964", citado en Kate Doyle "Double Dealing Mexico's Foreign Policy Toward Cuba", National Security Archive, 2 de marzo de 2003, https://nsarchive2.gwu.edu/NSAEBB/NSAEBB83/ index.htm

${ }^{73}$ William LeoGrande y Peter Kornbluh, op. cit., p. 132. Aquí, ambos autores relatan lo siguiente: "En noviembre de 1964, cuando Johnson se preparaba para reunirse con el nuevo presidente electo de México, Gustavo Díaz Ordaz, le preguntó a Rusk si debía protestar ante la decisión de México de mantener relaciones con la isla. 'Oh, yo no tocaría ese tema -respondió Rusk-. Durante la reunión de ministros de Relaciones Exteriores a finales de julio, varios de nosotros -Brasil y otros- hablamos sobre lo deseable que resultaba en el terreno práctico mantener una embajada latinoamericana allí si era posible. Así que el hemisferio se siente muy relajado ante el hecho de que los mexicanos permanezcan allí'". 


\section{CUADro 7}

Tamaño de los win-sets durante la reunión de la oEA en el voto para el rompimiento de relaciones diplomáticas con Cuba

\begin{tabular}{|l|c|c|c|c|c|}
\hline $\begin{array}{c}\text { Tipo de voto para } \\
\text { la expulsión }\end{array}$ & $\begin{array}{c}\text { Nivel I, } \\
\text { tablero 1 }\end{array}$ & $\begin{array}{c}\text { Nivel I, } \\
\text { tablero 2 }\end{array}$ & $\begin{array}{c}\text { Nivel II, } \\
\text { tablero 3 }\end{array}$ & $\begin{array}{c}\text { Nivel II, } \\
\text { tablero 4 }\end{array}$ & Total \\
\hline Abstención & 1 & 1 & 1 & 1 & 4 \\
\hline En contra & 2 & 1 & 2 & 0 & 5 \\
\hline A favor & 0 & 2 & 0 & 2 & 4 \\
\hline
\end{tabular}

2 equivale a amplio, 1 a medio y 0 a muy bajo

Fuente: elaboración propia.

En resumen, la actitud de México en la Ix Reunión de Consulta fue congruente con los principios de política exterior. La administración de López Mateos defendía vehementemente la no intervención en Cuba, pero eso no significaba que apoyara el comunismo. Para el PRI, esa posición era conveniente porque al mismo tiempo mandaba la señal de que México no estaría dispuesto a ningún tipo de intervención o crítica por sus propios excesos antidemocráticos y represivos. El mensaje subliminal era "no se entrometan en Cuba porque no queremos que interfieran en nuestros asuntos internos". Asimismo, es probable que México buscara guardar cierto equilibro con respecto al anterior voto de octubre de 1962 que fue de apoyo a Estados Unidos. Ahora le tocaba un apoyo más abierto a Cuba.

A pesar de que la decisión estuvo más inclinada a una naturaleza principista, la medida también tenía elementos pragmáticos. Más adelante, el gobierno mexicano apoyó a la CIA para espiar a los cubanos en México y enviaba la lista de pasajeros del vuelo Ciudad de México-La Habana. Es decir, el gobierno mexicano adoptó una política de doble juego. Por un lado, públicamente apoyaba a Cuba a través de los organismos internacionales y de un discurso basado en los principios de política exterior. Por el otro, en forma privada México 
apoyaba a Estados Unidos en su lucha contra el comunismo en el marco de la Guerra Fría. En otras palabras, el pragmatismo también prevaleció en este caso.

\section{Conclusiones}

Este texto presenta evidencia de que el gobierno de ALm no apoyó a la Cuba comunista de Castro. Previamente, México mostró cierta simpatía a la Revolución cubana porque encontraba ciertas similitudes con la mexicana. Sin embargo, el hecho que marcó un hito fue el discurso del 2 de diciembre de 1961, cuando Castro declaró que su movimiento era marxista-leninista. A partir de ese discurso, México adoptó una política prácticamente anticomunista; esa declaración marcó de manera definitiva la tendencia del voto mexicano en las tres reuniones de la oEA. En privado, México se alineó a los intereses de Estados Unidos; en público, adoptaba una política nacionalista en la que defendía sus principios. Sin embargo, esa posición no era a favor de Castro, sin que esencialmente se dirigía al consumo interno.

La principal evidencia de lo anterior es que, en su sexenio, el gobierno de ALM donó, según las fuentes consultadas, petróleo para la invasión a Bahía de Cochinos; ofreció la isla de Cozumel en caso de que Estados Unidos necesitara usarla como base aérea; mandaba la lista de pasajeros del vuelo Ciudad de México-La Habana a la cia; confiscó material comunista que se dirigía a Cuba; permitió a la cia espiar a los ciudadanos que ingresaban a la embajada cubana en la Ciudad de México; y acordó con Brasil y Estados Unidos mantener relaciones con Cuba para conveniencia de Washington. Aparentar que se apoyaba a Cuba en la oEA servía para demostrar autonomía frente a Estados Unidos; apaciguar a los grupos nacionalistas internos; evitar que Castro pudiera financiar a grupos terroristas en México y para la defensa tradicional de la política exterior principista. Los argumentos 
anteriores demuestran el uso del pragmatismo principista de México frente a Cuba.

Los tres casos que se analizan en este ensayo reflejan con claridad la utilidad del juego del doble nivel, de Robert Putnam. En efecto, el gobierno de López Mateos jugaba en cuatro pistas distintas al mismo tiempo. Por un lado, en su política hacia la Revolución cubana buscaba satisfacer a los grupos nacionalistas. Por el otro, la posición anticomunista satisfacía a los grupos de derecha. En lo externo, López Mateos tenía que encontrar un punto medio entre Estados Unidos y Cuba. Por un lado, trataba de proyectar una política exterior independiente de Washington basada en los principios tradicionales. Por el otro, necesitaba garantizar el apoyo de Estados Unidos en la economía nacional. Los tres votos en las reuniones de la oeA reflejan esta premisa. México recurrió a la abstención, la aprobación o el rechazo de acuerdo con circunstancias coyunturales relacionadas con el funcionamiento del sistema político mexicano y el marco de la Guerra Fría que enfrentaba a Estados Unidos y a la Unión Soviética en el sistema global. El gobierno de López Mateos no estaba a favor del comunismo, pero estaba en contra de la utilización de la oEA por Estados Unidos como un instrumento para avanzar en sus intereses frente a la Unión Soviética en el marco de la Guerra Fría. Además, México estaba tratando de defender su política tradicional basada en los principios de no intervención y de autodeterminación de los pueblos. Es decir, la política exterior tuvo una dosis alta de pragmatismo en el caso de los votos de México en la oEA entre 1962 y 1964.

México votó de manera diferenciada en las tres reuniones debido a distintos contextos tanto internos como externos. En la viıI Reunión de Consulta de 1962, el ambiente nacional fue estratégico. López Mateos estaba interesado en satisfacer los intereses de los grupos internos, sin aumentar la polarización. Es decir, al presidente no le convenía ampliar el debate y las diferencias entre los grupos nacionalistas y de derecha porque ello podría afectar la propia estabilidad 
del sistema político. Así, el discurso para defender la incompatibilidad del comunismo en la oeA estaba dirigido a los grupos de derecha. La abstención y la reserva incluida en el acta final fue una señal para los grupos de izquierda. Ambos grupos quedaron satisfechos y la polarización, al menos en el tema cubano, disminuyó en ese momento. La misma lógica es válida para el caso de Estados Unidos. La incompatibilidad iba dirigida a los oídos estadounidenses, mientras que la abstención y la reserva en el acta final eran un guiño a Castro. De este modo, México tuvo que recurrir a un pragmatismo principista para poder alcanzar sus objetivos. En el segundo voto, el ambiente internacional prevaleció. La presión de Estados Unidos determinó el proceso de toma de decisiones de ALM y México no tuvo mucho espacio de maniobra, si bien buscó mostrar cierta autonomía y satisfacer a los grupos nacionalistas. A pesar de dar un apoyo a la resolución global, México votó con abstención en párrafos específicos e incluyó una reserva de naturaleza principista, lo que le imprimió, asimismo, un sesgo de pragmatismo principista. En el tercer voto, el contexto interno tuvo mayor influencia. La cercanía de las elecciones presidenciales y el fin del sexenio marcaron el voto de México en la Ix Reunión de Consulta en 1964, que fue un voto en contra; el factor externo tuvo un peso menor. El foco de la Guerra Fría ya no era Cuba y Estados Unidos estaba concentrado principalmente en sus problemas internos. Incluso la presión más fuerte para el rompimiento de relaciones con Cuba no provenía de Washington, sino de los países duros latinoamericanos, como Venezuela y Colombia.

Un hallazgo relevante en esta investigación es que la administración de López Mateos tomó la decisión de sus votos en función de los win-sets. Es decir, México adoptó las opciones que representaban mayores ventajas y ganancias tanto internas como externas. En cada momento, el tamaño del win-set fue diferente y ello explica por qué los votos fueron distintos. Por lo tanto, es posible afirmar que la teoría de los 
win-sets de Robert Putnam es muy útil para explicar las decisiones de política exterior de México en un contexto de relación trilateral, como es el caso de México-Estados Unidos-Cuba. Asimismo, esta noción es útil en los casos en que internamente hay una división, en éste, en dos grupos prácticamente antagónicos. Sería deseable que este marco teórico pudiera utilizarse para futuras investigaciones en temas similares.

El uso de la teoría de los win-sets puede sembrar una semilla en futuras investigaciones sobre la política exterior de México. Esta investigación demostró que estas nociones pueden utilizarse para explicar el proceso de toma de decisiones bajo presiones internas y externas, y para avanzar en los intereses propios y de la contraparte. Una hipótesis para futuras investigaciones es que el grupo de presión más unido, organizado y con recursos económicos puede resultar más efectivo para influir en el proceso de toma de decisiones de la política exterior de México. De la misma manera, el grupo menos organizado, más débil y polarizado, tendrá menor capacidad de influencia. En los vínculos exteriores de México, Estados Unidos es un factor clave. Por ello, cada gobierno debe establecer estrategias para encontrar un punto medio entre mostrar autonomía y cooperar con Washington. De la misma forma, la opinión pública mexicana preferirá una política más cercana y de solidaridad con los países de América Latina. El gobierno de México debe buscar una fórmula efectiva para lidiar con estos cuatro tableros de juego. La opción del pragmatismo principista es una alternativa que puede ser eficaz.

\section{REFERENCIAS}

Archivos

Archivo Histórico de la Secretaría de Relaciones Exteriores (AHSRE), III-5660-11 1A. 
Archivo Histórico de la Secretaría de Relaciones Exteriores III-5648-1

Archivo Histórico de la Secretaría de Relaciones Exteriores III-5660-11

Archivo Histórico de la Secretaría de Relaciones Exteriores SPR-413-1

Archivo Histórico de la Secretaría de Relaciones Exteriores $\mathrm{XII} / 441.2(\mathrm{X}) / 1$.

Departamento de Estado, Foreign Relations of the United States, 1961-1963, Volume XII, American Republics

Organización de los Estados Americanos, OEA/SER.G/III, C-sa-463

\section{Documentos oficiales}

Congreso de Estados Unidos, "Punta Del Este Conference, January 1962: Report of Senators Wayne Morse and Bourke B. Hickenlooper to the Committee on Foreign Relations, United States Senate", marzo de 1962, t.ly/dI01

Departamento de Estado, "147. Memorandum of Conversation", en Foreign Relations of the United States, 1961-1963, Volume XII, American Republics, Ciudad de México, 29 de junio de 1962.

Departamento de Estado, "Telegram 144 From Secretary of State

Rusk to the Department of State, Punta del Este”, en Foreign Relations of the United States, 1961-1963, Volume XII, 31 de enero de 1962.

Departamento de Estado, "Circular telegram 700 to all Latin American posts, October 21. Instructions for Ambassadors following the President's nationwide TV statement on Soviet offensive nuclear capability in Cuba", Top Secret. 5 pp. DOS, CF, 737.00/10-2262, en Foreign Relations of the United States, 1961-1963, vol. xII, American Republics.

Gobierno de México, Presencia internacional de Adolfo López Mateos, México, 1963.

Lyndon B. Johnson Library, National Security Files CO-Mexico, "Díaz Ordaz visit, 1964", citado en Kate Doyle "Double Dealing Mexico's Foreign Policy Toward Cuba", National Security Ar- 
chive, 2 de marzo de 2003, https://nsarchive2.gwu.edu/NSAE BB/NSAEBB83/index.htm

Organización de los Estados Americanos, oEA, "Acta Final de la Octava Reunión de Consulta de Ministros de Relaciones Exteriores para Servir de Órgano de Consulta en Aplicación del Tratado Interamericano de Asistencia Recíproca”, https:/ / www.oas.org/consejo/sp/rc/rcactas.asp

Organización de los Estados Americanos, "Resolution of the Council of the Organization of the American States", 23 de octubre de 1962, OAS Doc. OEA/SER.G/III, C-sa-463.

Organización de los Estados Americanos, "Acta de la sesión extraordinaria celebrada el 23 de octubre de 1962", Consejo de la OEA.

Organización de los Estados Americanos, “Acta Final Novena Reunión de Consulta de Ministros de Relaciones Exteriores para servir de órgano de consulta en aplicación del Tratado Interamericano de Asistencia Recíproca, Washington D.C., 21 a 26 de julio de 1964", http:/ /www.oas.org/consejo/sp/RC/RCac tas.asp

Secretaría de Relaciones Exteriores, SRE, "Discurso pronunciado por el señor don Manuel Tello, secretario de Relaciones Exteriores en la Primera Sesión Plenaria de la vini Reunión de Ministros de Relaciones Exteriores de las Repúblicas Americanas, efectuada en Punta del Este, Uruguay, el día 24 de enero de 1962", Serie Problemas Nacionales e Internacionales, México, 1962.

Secretaría de Relaciones Exteriores, SRE, "Relanzamiento de la relación México-Cuba”, https://www.gob.mx/sre/documentos/ 68206

Secretaría de Relaciones Exteriores, SRE,"Informe sobre la Octava Reunión de Consulta de Ministros de Relaciones Exteriores que presenta el secretario general de la Delegación de México, Manuel Tello Macías", en AHSRE III-5660-11 1A.

Secretaría de Relaciones Exteriores, SRE, "Palabras pronunciadas por el Senador Lic. Antonio Mena Brito. Secretario de la Gran Comisión, ante el señor Secretario de Relaciones Exteriores, 
antes de su partida a la Conferencia de Punta del Este, en representación de un grupo de Senadores", AHSRE, SPR-413-1. Secretaría de Relaciones Exteriores, SRE, Dirección General de Prensa y Publicidad, Boletín de Prensa núm. 93, 15 de julio de 1964. Expediente, III-5660-11.

Secretaría de Relaciones Exteriores, SRE, “OEA. Apuntes para la intervención del Representante de México en el debate general de la Novena Reunión de Consulta de Ministros de Relaciones Exteriores para servir de Órgano de Consulta en aplicación del TIAR", XII/441.2(X)/1.

\section{Memorias}

Covarrubias, Ana y Laura Muñoz, Manuel Tello: por sobre todas las cosas, México, México, Secretaría de Relaciones Exteriores, 2007.

Tello, Manuel, México, Una posición internacional, México, Joaquín Mortiz, 1972.

\section{Artículos}

BArcia, Camilo, "Discrepancias Interamericanas. La Segunda Conferencia de Punta del Este", Revista de Política Internacional, Madrid, mayo-junio 1962.

Bernstein, Enrique, "Punta del Este y las erróneas interpretaciones de un tratado", Foro Internacional, vol. II, 4 (8) abril-junio, 1962, pp. 518-534.

Bobadilla, Leticia, "La exclusión de Cuba de la Organización de Estados Americanos: los desacuerdos diplomáticos entre México y Estados Unidos en 1962”, Istor: revista de historia internacional, año 9, núm. 33, 2008, págs. 58-76.

Covarrubias, Ana, "Cuba and Mexico: A Case for Mutual Nonintervention”, Cuban Studies, 26, 125, 1996.

Fenn, Peggy, "México, la no intervención y la autodeterminación en el caso de Cuba", Foro Internacional, 4 (1 [13]), 1963. 
Fernández, Félix, "Octava Reunión de Consulta de Ministros de Relaciones Exteriores de América”, Revista Política Internacional, 61 (1962), pp. 119-131.

Gómez Robledo, Antonio, "La crisis actual del sistema interamericano", Foro internacional, vol. III, 2 (10) octubre-diciembre, 1962, pp. 176-208.

Jamison, Edward, "Cuba and the Inter-American System: Exclusion of the Castro Regime from the Organization of American States", The Americas, vol. 36, núm. 3 (enero de 1980), pp. 317-346.

KeLLER, Renata, "A foreign policy for domestic Consumption: Mexico's Lukewarm Defense of Castro, 1959-1969”, Latin American Research Review, vol. 47, núm. 2, 2012, pp. 100-119.

Keller, Renata, "Responsibility of the Great Ones': How the Organization of American States and the United Nations Helped Resolve the Cuban Missile Crisis", Journal of Latin American Studies, 2019, pp. 1-22.

López, Arturo, "Cuba y la oEA: cambio y continuidad", América Latina Hoy, España, vol. 52, enero de 2010, https://revistas.usal. es/index.php/1130-2887/article/view/5678

MacDonald, R. St. J., "The Organization of American States in Action”, The University of Toronto Law Journal, vol. 15, núm. 2, 1964.

Neto, Helio, "Independent Foreign Politics in action: An Overview of the Punta del Este Convention in 1962", Revista Brasileira de Política Internacional, 48 (2), 2005, pp. 13-14.

OJEDA, Mario, "Las relaciones de México con el régimen revolucionario cubano", Foro Internacional, 14 (4 ([56]), 1974, pp. 474-506.

Pellicer, Olga, "México en la oeA", Foro Internacional, 6(2/3 [22-23]), 1965, pp. 290-293.

Pellicer, Olga, "La revolución cubana en México", Foro Internacional, vol. viII, 4 (32) abril-junio, 1968.

Pellicer, Olga, "Los grupos patronales y la política exterior mexicana: las relaciones con la Revolución cubana”, Foro Internacional, 101 (37), 21, 1969.

Rodríguez, María Elena, "Sobre la incomprensión a la postura mexicana frente a Cuba”, Foro Internacional, vol. vi, 1 (21), julio-septiembre, 1965, pp. 121-135. 
SuÁrez, Ana Rosa, "México, los Estados Unidos y la política interamericana durante el gobierno de Lyndon B. Johnson (19631968)", Revista Iztapalapa, (17), 1989, pp. 51-66.

Tello, Carlos, "México frente a la expulsión de Cuba de la Organización de Estados Americanos", Cuadernos Americanos: Nueva época, 2 (136), 2011.

Wien, Arthus, "Le prix de l'ostracisme de Cuba de l'oea en 1962: les dessous de la conférence de Punta del Este", Nouveaux mondes mondes nouveaux, http://journals.openedition.org/nuevomun do/70502

\section{Libros}

Alexandrov, Stanimir, Self-Defense Against the Use of Force in International Law, La Haya, Kluwer Law International, 1996.

Allison, Graham, Essence of decision, Explaining the Cuban Missile Crisis, E.U., Harper Collins, 1971.

Bobadilla, Leticia, México y la oea: los debates diplomáticos, 19591964, México, sRe, 2006.

Covarrubias, Ana, Historia de las relaciones internacionales de México, 1821-2010 (Caribe), México, sRe, 2011.

Covarrubias, Ana, "México y la Revolución cubana: la independencia de un país dependiente", en Arturo C. Sotomayor Velázquez y Gustavo Vega Cánovas (coords.), El mundo desde México: ensayos de política internacional. Homenaje a Olga Pellicer, México, El Colegio de México, 2008, pp. 25-46.

Foweraker, Joe y Ann Craig, Popular movements and political change in Mexico, Boulder, Rienner, 1990.

Keller, Renata, Mexico's Cold War: Cuba, the United States, and the Legacy of the Mexican Revolution, Cambridge, University Press, 2015.

Kennedy, Robert, Thirteen Days: A Memoir of the Cuban Missile Crisis, Nueva York, Norton and Company, 1969.

Lajous, Roberta, Historia Minima de las Relaciones Exteriores de México, México, El Colegio de México, 2012. 
LeoGrande, William y Peter Kornbluh, Diplomacia encubierta con Cuba. Historia de las negociaciones secretas entre Washington y La Habana, México, FCE, 2015.

Morales, Minerva, Aspectos políticos del sistema interamericano: las reuniones de cancilleres, México, UnAM, 1961.

Morley, Jefferson, Our Man in Mexico: Winston Scott and the Hidden History of the CIA, Kansas, University Press, 2008.

OJeDa, Mario, Alcances y límites de la política exterior de México, México, El Colegio de México, 1976.

OJedA, Mario, México y Cuba revolucionaria: cincuenta años de relación, México, El Colegio de México, 2008.

Pellicer, Olga, México y la Revolución cubana, México, El Colegio de México, 1972.

Putnam, Robert, "Diplomacy and Domestic Politics: The Logic of Two-Level Games", en Peter Evans et al., Double-Edged Diplomacy, EE.uU., University of California Press, 1993.

Schiavon, Jorge A., "La relación especial México-Estados Unidos: cambios y continuidades en la guerra y posguerra fría", en Jorge A. Schiavon et al., En busca de una nación soberana: relaciones internacionales de México, siglos XIX y XX, México, CIDE-SRE, 2006.

Tello, Carlos, El fin de una amistad. La relación de México con la Revolución cubana, México, Planeta, 2005.

Waltz, Kenneth, The Man, the State, and the War. A Theoretical Analysis, Nueva York, Columbia University Press, 2001.

White, Christopher, Creating a Third World: Mexico, Cuba, and the United States during the Castro Era, Albuquerque, University of New Mexico Press, 2007.

Tesis

Arnaud, Roberto, Amistad por conveniencia: La política exterior de México hacia Cuba de 1959 a 2006, México, udLA, 2006.

Cárdenas, Nuty, México-Cuba, 1958-1964: punto de acuerdo en la relación México-Estados Unidos, México, CIDE, 2005.

Covarrubias, Ana, Mexican-Cuban Relations, 1959-1988, Reino Unido, Oxford University, 1994. 
Koslow, Lawrence, Mexican Foreign Policy Decision-Making: The Mutual Adjustment of Needs and Independence, EE.UU., University of California, Riverside, 1969.

PEÑA, Félix, Las sanciones en el sistema interamericano. La expulsión de un Estado miembro de la Organización de los Estados Americanos, España, Universidad de Madrid, 1965.

Trejo, Abraham, "México en la estrategia estadounidense de contención del comunismo en América Latina: la cuestión cubana en la relación de Washington con el régimen priísta (19591964)”, Licenciatura en Relaciones Internacionales, FCPYs, UNAM, 2011.

Smith, Arthur, Mexico and the Cuban Revolution: Foreign Policy Making in Mexico Under President Adolfo López Mateos (1958-1964), EE.UU., Cornell University, 1970.

\section{Periódicos y revistas}

"Acordaron aplicar sanciones a Cuba, por 15 votos contra 4", $\mathrm{El}$ Universal, 26 de julio de 1964, p. 1.

"Alza notable en la Bolsa de Valores", El Universal, 26 de enero de 1962, p. 1.

De la Garza, Rafael, "De Cuba a Venezuela: la decadencia de la diplomacia mexicana”, La Jornada, 5 de abril de 2017, http:/ / jornadaveracruz.com.mx/Post.aspx?id=170405_072846_428

"Excluyeron de la oEA a Cuba; Su comunismo es incompatible", $E l$ Universal, 31 de enero de 1962, p. 1.

"Gran peligro para toda América es el régimen de cuba, reitera la patronal", El Universal, 23 de enero de 1962, p. 1.

"Habla Tello sobre el voto de México", El Universal, 24 de octubre de 1962, p.1.

"Las sanciones son de obligatorio cumplimiento", El Universal, 26 de julio de 1964, p. 4.

Méndez, Pablo "La expulsión de Cuba en Punta del Este", Montevideo Portal, 8 de abril de 2015, https:/ /www.montevideo.com. uy/Noticias/La-expulsion-de-Cuba-en-Punta-del-Este-uc 267404 
Rock, Roberto, "El solitario de Montevideo", El Universal, 8 de marzo de 2019, https://www.eluniversal.com.mx/columna/roberto-rock-l/nacion/el-solitario-de-montevideo

Rodríguez, Esteban, "Durante la 'Guerra Fría', el país fue terreno para la lucha de espías”, El Universal, 28 de septiembre de 2001, https://archivo.eluniversal.com.mx/nacion/67021.html.

"Se han formado tres grupos en el seno de la oEA", El Universal, 21 de julio de 1964, p. 9.

Stone, Thomas, "U.s. Yields on Cuban oAs Move", The Washington Post, 31 de enero de 1962, p. 1.

Szulc, Tad, O.A.s. "Votes to Deny Cuba any Inter-American Role; Prohibits trade in Arms", The New York Times, 31 de enero de 1962, p. 1.

Torre, Wilbert, "Traición mexicana a Cuba", El Universal, 3 de febrero de 2008, https://archivo.eluniversal.com.mx/primera/ 30398.html 
